\title{
Fabian Kolb
}

\section{Klingende ımaiestas papalis` zwischen Hermeneutik und Präsenz Raum-, Zeit- und Medialitätskonzepte papstbezogener Kompositionen um 1400}

$»$ In omnem terram exivit sonus eorum, et in fines orbis terrae verba eorum. « ${ }^{1}$ Als Ulrich von Richental seiner um 1420 verfassten Chronik des Konstanzer Konzils (1414-1418) das Psalm 19.5 bzw. Römerbrief 10.18 entnommene Motto voranstellte, wählte er eine Devise, die die Tragweite der Konstanzer Ereignisse unter explizitem Verweis auf ihre kosmopolitischweltumspannende Relevanz und geographisch-geopolitischen Dimensionen unterstrich. ${ }^{2}$ Als hierfür maßgeblich stellte er dabei signifikanterweise primär die Bedeutung des >sonus $<$, also das Medium der Klanglichkeit, heraus. Dass er in diesem Kontext zudem just einen Bibelvers wählte, auf den über die entsprechende Choralzeile auch etliche Kompositionen aus dem zeitgenössischen Repertoire der Ars subtilior rekurrierten - und zwar gerade solche, die wie Apollinis eclipsatur oder Sub Arturo plebs in selbstreflexiv-metareferenzieller bzw. autopoetischer Weise auf die Spezifika und Bedingtheiten ihres Mediums Musik abhoben ${ }^{3}$-, ist ebenso bezeichnend, mag dies doch - einge-

1 »Über die ganze Erde reichte ihr Klang, und bis an die Enden der Welt ihre Worte.« Konstanz, Rosgartenmuseum Inv. Hs. 1, Vorsatzblatt, nicht foliiert. Eine Reproduktion der Konstanzer Handschrift liegt vor: Ulrich Richental. Chronik des Konstanzer Konzils 1414-1418. Mit Geleitwort, Bildbeschreibung und Textübertragung in unsere heutige Sprache, hrsg. von Michael Müller, Konstanz ${ }^{2}$ 1984; eine neue Faksimile-Edition ist für das 600-Jahr-Jubiläum 2014 geplant. Die jüngste Textedition der Richental-Chronik ist 2010 erschienen: Chronik des Konstanzer Konzils 1414-1418 von Ulrich Richental, eingeleitet und hrsg. von Thomas Martin Buck, Ostfildern 2010 (Konstanzer Geschichts- und Rechtsquellen, 41). Vgl. insgesamt auch: Wilhelm Matthiessen, »Ulrich Richentals Chronik des Konstanzer Konzils. Studien zur Behandlung eines universalen Großereignisses durch die bürgerliche Chronistik «, in: Annuarium Historiae Conciliorum 17 (1985), S. 71-191 und 323-455; sowie Thomas Rathmann, Geschehen und Geschichten des Konstanzer Konzils. Chroniken, Briefe, Lieder und Sprüche als Konstituenten eines Ereignisses, München 2000 (Forschungen zur Geschichte der älteren deutschen Literatur, 20).

2 Hierauf scheint in der Tat ganz maßgeblich die gesamte Anlage der Chronik (inklusive ihres minutiösen Teilnehmerverzeichnisses und heraldischen Appendix) ausgerichtet.

3 Edition in: Two 14th-Century Motets in Praise of Music, hrsg. von Margaret Bent, North Harton 1977 (Antico Edition, 15), S. 8-13. Vgl. hierzu unter anderen Laurenz Lütteken, »Autobiographische $<$ Musik? Kompositorische Selbstdarstellung in der Motette des 14. und 15. Jahrhun- 
denk aller Überlieferungsproblematik - durchaus im Sinne einer Art spezifisch musikalischen Emblems als potenzieller Subtext des Psalmvorspruchs mitbedacht worden sein.

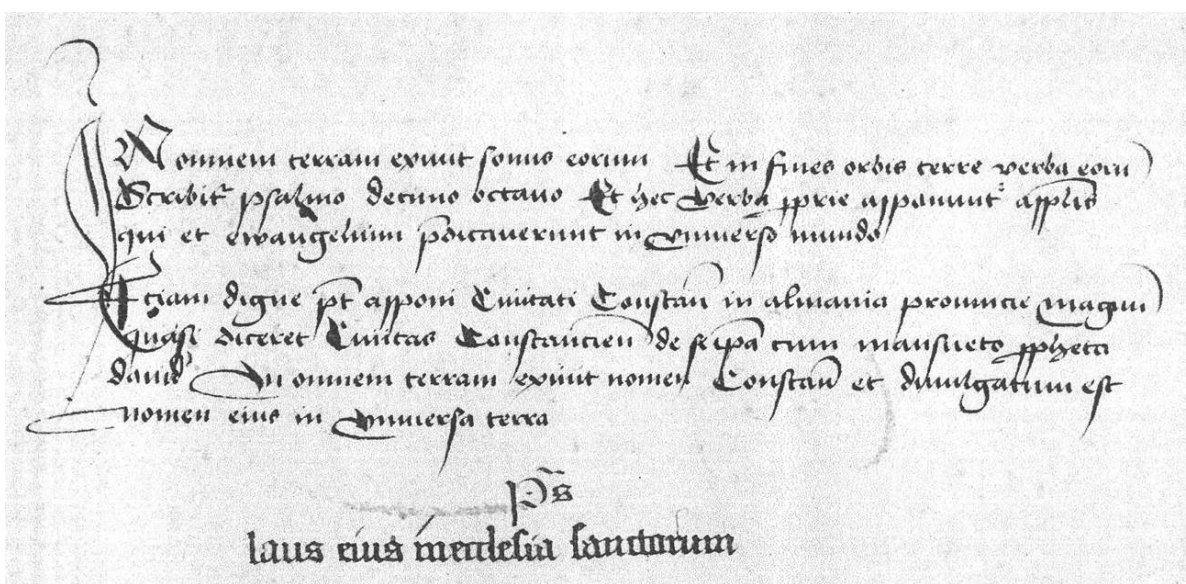

Abbildung 1: Ulrich von Richental, Chronik des Konstanzer Konzils (Konstanz, Rosgartenmuseum Inv. Hs. 1, Vorsatzblatt, nicht foliiert)

In der Tat schenkte Richental der Musik in seinem retrospektiven (zweifellos dramatisierend-inszenatorischen, idealisierend-panegyrisch überformten, zugleich jedoch erstaunlich präzisen) Rapport ${ }^{4}$ auffallend große Beachtung. Immer wieder verwiesen wird auf ihren vielfältigen Einsatz als klangliches Medium öffentlicher Inszenierung gerade bei solch zentralen Ereignissen und bedeutsamen Begebenheiten wie beispielsweise der Konzilseröffnung,

derts«, in: Deutsche Vierteljahresschrift fïr Literaturwissenschaft und Geistesgeschichte 74 (2000), S. 3-26. Die Selbstbezüglichkeit vieler Kompositionen in der Zeit um 1400 ist noch nicht umfassend aufgearbeitet; vgl. etwa Anne Stone, »Self-reflexive songs and their readers in the late 14th century«, in: Early Music 31 (2003), S. 180-194; Jehoash Hirshberg, »Criticism of Music and Music as Criticism in the Chantilly Codex«, in: A Late Medieval Songbook and Its Context. New Perspectives on the Chantilly Codex (Bibliothèque du Château de Chantilly, Ms.564), hrsg. von Yolanda Plumley und Anne Stone, Turnhout 2009, S. 133-159; sowie Elizabeth Randell Upton, » Apres vos fais $<$. Machaut Reception as Seen Through the Chantilly Codex (F-CH 564)«, in: Music, Dance, and Society. Medieval and Renaissance Studies in Memory of Ingrid G. Brainard, hrsg. von Ann Buckley und Cynthia J. Cyrus, Kalamazoo 2011, S. 189-210.

4 Vgl. Thomas Martin Buck, » $\mathrm{Zu}$ den historiographischen Prinzipien Ulrich Richentals«, in: Schriften des Vereins für Geschichte des Bodensees und seiner Umgebung 117 (1999), S. 11-32; ders., »Fiktion und Realität. Zu den Textinserten der Richental-Chronik«, in: Zeitschrift fïr die Geschichte des Oberrheins 149 (2001), S. 61-96. 
der Ankunft König Sigismunds, bei Heiligsprechungen und Segnungen, Prozessionen und anderen Feierlichkeiten sowie der Papstwahl. ${ }^{5}$ Von besonders eminenter Wichtigkeit erscheint ihre Funktion so insbesondere auch in der symbolhaft höchstgradig aufgeladenen Zeremonie anlässlich von Papstweihe und -krönung, zu der Richental in permanentem Rekurs auf die musikalische Ausgestaltung vermerkte:

Und do er kam zů dem Helmhus, do stůnd er ab und ging ze fưß in daz münster. Da sungend sy Te deum laudamus und Veni sancte spiritus mit ainr collect. ... Und nach der mess, do satzt man den bapst nider uff ainen stůl zwüschen dem fronalltar und dem sigental [= Sakristei $]$, und fieng man inn an ze băpst wihen. Und satzt man dar ain tisch mit brott und win, als man gewonlich bischoff wihet. Und gǒß man öl uff sin hopt, und verband im daz hobet mit ainem wissen tůch. Und stůndent uff dem altar siben silbrine vergülti kertzstal mit siben brinnenden großen kertzen, und sust vil großer brinnender kertzen, der waz one zal. Och was uff dem altar Sant Conratz und Sant Pelayen höpter, und och des bapstes infel mit den dryn kronen, und sust sin infel. Und als man anfieng, do sang man ainest die letany in latin und ainest in kriechischer sprach. ... Und sang mit luter stimm: Pater sancte, sic transit gloria mundi. Daz ist: Hailiger vatter, also zergăt die er der welt. Do antwort der bapst: Deo gratias. Und gieng damit uffhin zů des lüpriesters altar. In der session hett der băpst mess, und sang man in der mess ain epistel in latin und aine in kriechischer sprach. Und das ewangelium och ains in latin und daz ander in kriechischer sprach. Und sang man zway Gloria in excelsis. ... Und stůnd der ain patriarch vor im und hatt die infel mit den dryen kronen und mit dem guldin crütz in siner hand. ... Und brunnend uff der brügi so vil

5 Insgesamt waren die Konzilien der Zeit bekanntlich Brennpunkte des aktuellen musikalischen Lebens sowie des Musiker- und Repertoireaustauschs. Die Rolle der Musik während des Konstanzer Konzils ist aufgearbeitet bei Manfred Schuler, »Die Musik in Konstanz während des Konzils 1414-1418«, in: Acta musicologica 38 (1966), S. 150-168; kontextualisierend auch: Reinhard Strohm, The Rise of European Music 1380-1500, Cambridge ${ }^{3} 2005$, S. 106-124 (»The Council of Constance «). Vgl. ferner: Elisabeth Vavra, »Te deum laudamus zur Zeit des Konstanzer Konzils (1414-1418)«, in: Das Fest. Eine Kulturgeschichte von der Antike bis zur Gegenwart, hrsg. von Uwe Schultz, München 1988, S. 127-139; Gerrit Jasper Schenk, »Sehen und gesehen werden. Der Einzug König Sigismunds zum Konstanzer Konzil $1414 \mathrm{im}$ Wandel von Wahrnehmung und Überlieferung (am Beispiel von Handschriften und frühen Augsburger Drucken der Richental-Chronik)«, in: Medien und Weltbilder im Wandel der Frühen Neuzeit, hrsg. von Franz Mauelshagen und Benedikt Mauer, Augsburg 2000, S. 7l106; sowie grundsätzlich: Barbara Stollberg-Rillinger, »Zeremoniell, Ritual, Symbol. Neue Forschungen zur symbolischen Kommunikation in Spätmittelalter und Früher Neuzeit«, in: Zeitschrift für historische Forschung 27 (2000), S. 389-405; Thomas Weller, »Ordnen - Gemeinschaft stiften - Ins Recht setzen. Die Funktion von Ritualen und ihr Wandek, in: Spektakel der Macht. Rituale im Alten Europa. Katalog, hrsg. von Barbara Stollberg-Rillinger u.a., Darmstadt 2008, S. 199-203. Zur zeremoniellen Einbindung der Musik noch immer grundlegend: Sabine Žak, Musik als »Ehr und Zier« im mittelalterlichen Reich. Studien zur Musik im höfischen Leben, Recht und Zeremoniell, Neuss 1979. 
großer kertzen, daz man ir nit zellen kond. Und sungend da also gemach, daz ich es ni[t] verstan mocht. Darnach kam ain patriarch, der trůg ain güldin crütz in siner hand, und knüwot mit dem crütz für den bapst. Und kam darnach ain bischoff, der trůg ain steken in siner hand, und was ain busch werch an. Daz zündet man an. daz verbran an stett. Do růft der bischoff: Pater sancte, sic transit gloria mundi. Do antwurt der bapst: Deo gratias. Daz beschach zway mal, und sungend aber gemächlich. Darnach stund uff der cardinal Pangracius, der cardinal de Comitibus, der cardinal de Flischgo, daz sind dry ewangelier cardinäl, und hort daz ampt zů inen. Und stůnd der hochmaister von Rodiß zů inn, und knüwotend alle vier nider, und stůndent wider uff und namen die infelen von dem patriarchen und trůgend sy also die stegen uffhin zů dem bapst. Und die senger sungend vast wol. Daz werot wol ain stund. Und die infelen satztend sy dem bapst uff sin hopt. ... Darnach kam des bapstes crütz, und nach dem die senger, die stäteklich sungen. ${ }^{6}$

\section{Musikalische Medialität und päpstliches Zeremoniell}

Welch zentrale Signifikanz der Musik im Zuge des päpstlichen Zeremoniells zukam - und zwar nicht nur quantitativ über ihren unentwegten Einsatz als quasi-konstanten $>$ soundscape $<$, sondern qualitativ über das ihr eingeschriebene Funktions-, Wirkungs- und Symbolspektrum -, lässt sich freilich nur unzulänglich anhand eines eher nüchtern-offiziösen Dokuments wie den zitierten Notizen ermessen. Denn wie sich - vor den vielfach überblendeten Ebenen der ästhetisch-philosophischen, ontologisch-eschatologischen, liturgisch-rituellen und wahrnehmungstheoretisch-medialen Vorstellungswelten des Spätmittelalters - näherhin die Wirkmechanismen, Konfigurationen und impliziten Botschaften manifestierten, die in der Musik gleichsam aufgehoben waren bzw. durch sie transportiert wurden, bleibt hier allenfalls schlagwortartig indiziert und nur implizit zwischen den Zeilen lesbar. Im Grunde vergleichbar den päpstlichen Zeremonienbüchern der Zeit ${ }^{7}$ wird der Einsatz von Musik zwar protokollarisch vermerkt und lokalisiert; über die der Musik dabei (wie selbstverständlich?) zugedachten speziellen Qualitäten, Potenziale und Obliegenheiten erfährt man indes kaum Konkreteres.

6 Zitiert nach: Chronik des Konstanzer Konzils 1414-1418 (wie Anm. 1), S. 109-113.

7 Vgl. Bernhard Schimmelpfennig, Die Zeremonienbücher der römischen Kurie im Mittelalter, Tübingen 1973 (Bibliothek des Deutschen Historischen Instituts in Rom, 40), für die hier relevante Zeit insbesondere: S. 36-131 und 148-337. Letztlich scheint der Befund für die Jahrzehnte um 1400 ganz ähnlich wie für die spätere Zeit diagnostiziert von Jörg Bölling, Das Papstzeremoniell der Renaissance. Texte - Musik - Performanz, Frankfurt am Main u.a. 2006 (Tradition - Reform - Innovation, 12). Vgl. zu diesem Problemkreis auch den Beitrag von Melanie Wald-Fuhrmann im vorliegenden Band. 
Plastischer allerdings wird das Bild in Verbindung mit einem Blick auf die entsprechenden Illustrationen, wie sie Richentals Chronik in nicht weniger als sieben Bildhandschriften ab 1460 beigefügt wurden und wie sie Musik eben auch ikonographisch mehrfach gezielt in Szene setzen. ${ }^{8}$ So lassen sich auf der bekannten Darstellung der Krönung Martins V. durch zwei Kardinäle und den Hochmeister von Rhodos aus der ca. 1465 angefertigten Konstanzer Handschrift ${ }^{9}$ (siehe Abbildung 2) jenseits schierer Faktizität auf gleichsam symbolisch-piktoraler Ebene ganz verschiedene, eng ineinander verwobene Aspekte und Funktionszusammenhänge von Musik ausmachen: Zum einen ist es fraglos das Modell von Decorum und prachtvoller Aufmerksamkeitssteigerung ${ }^{10}$ sowie der Repräsentationscharakter, aufgrund dessen Musik - man beachte die sorgsame Mise-en-page mit der Positionierung

8 Namentlich das Aulendorfer, das Prager und das Konstanzer Manuskript sind hier von Belang. Vgl. Lilli Fischel, »Die Bilderfolge der Richental-Chronik, besonders der Konstanzer Handschrift«, in: Das Konzil zu Konstanz, Bd. 2: Kommentar und Text, Starnberg und Konstanz 1964, S. 37-55; Bernd Konrad, »Die Buchmalerei in Konstanz, am westlichen und am nördlichen Bodensee von 1400 bis zum Ende des 16. Jahrhunderts«, in: Buchmalerei im Bodenseeraum 13. bis 16. Jahrhundert, hrsg. von Eva Moser, Friedrichshafen 1997, S. 109-154 und 259-331; Thomas Cramer, »Bilder erzählen Geschichte. Die Illustrationen in Ulrich Richentals Chronik als Erzählung in der Erzählung «, in: Erzäblungen in Erzäblungen. Phänomene der Narration in Mittelalter und Früher Neuzeit, hrsg. von Harald Haferland und Michael Mecklenburg, München 1996 (Forschungen zur Geschichte der älteren deutschen Literatur, 19), S. 327-349; Gisela Wacker, Ulrich Richentals Chronik des Konstanzer Konzils und ibre Funktionalisierung im 15. und 16. Jabrhundert. Aspekte zur Rekonstruktion der Urschrift und zu den Wirkungsabsichten der überlieferten Handschriften und Drucke, Diss. Tübingen 2001 (http://tobias-lib.unituebingen.de/volltexte/2002/520/); sowie Thomas Martin Buck, »Figuren, Bilder, Illustrationen. Zur piktoralen Literalität der Richental-Chronik«, in: Scientia veritatis. Festschrift für Hubert Mordek, hrsg. von Oliver Münsch und Thomas Zotz, Ostfildern 2004, S. 411-443 (mit Bildsynopse). Vgl. zum Kontext auch: Cinzia Procacci, »Re David. Simbolismo e realtà strumentale. Uno sguardo all'iconografia perugina dal XIII al XVI secolo«, in: Musica e immagine. Tra iconografia e mondo dell'opera, hrsg. von Biancamaria Brumana und Galliano Ciliberti, Florenz 1993 (Historiae Musicae Cultores Biblioteca, 70), S. 53-70; Pier Maurenzio Della PortaEnzio Genovesi, »Annunci e segnali. Il suono della tromba dalle immagini del primo Quatrocento«, in: ebda., S. 71-85; Björn R. Tammen, Musik und Bild im Chorraum mittelalterlicher Kirchen 1100-1500, Berlin 2000; Visualisierungsstrategien in mittelalterlichen Bildern und Texten, hrsg. von Horst Wenzel und C. Stephen Jaeger, Berlin 2006 (Philologische Studien und Quellen, 195); sowie Zwischen Wort und Bild. Wabrnehmungen und Deutungen im Mittelalter, hrsg. von Hartmut Bleumer u.a., Köln u.a. 2010.

9 Konstanz, Rosgartenmuseum Inv. Hs. 1, fol. $103^{\text {r }}$.

10 Vgl. zum Kontext: Peter von Moos, »Attentio est quaedam sollicitudo<. Die religiöse, ethische und politische Dimension der Aufmerksamkeit im Mittelalter «, in: ders., Rhetorik, Kommunikation und Medialität. Gesammelte Studien zum Mittelalter, Berlin 2006 (Geschichte. Forschung und Wissenschaft, 15), Bd. 2, S. 265-306. 


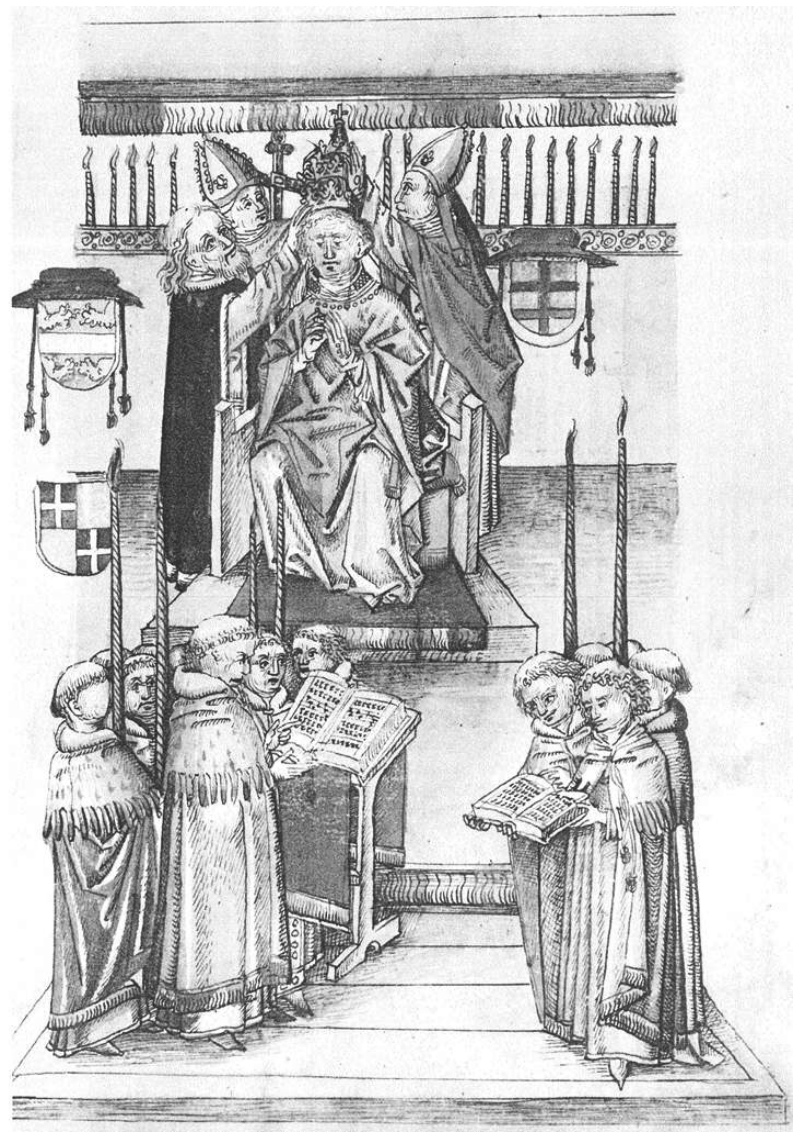

Abbildung 2:
Krönung Martins V.
(Konstanz,
Rosgartenmuseum
Inv. Hs. 1, fol. $103^{r}$ )

der Sänger seitlich im unteren Drittel des Bildes - gleichermaßen zu Fundament und Rahmung der hier inaugurierten päpstlichen Macht wird. Im Grunde dient sie damit (in Bildfindung wie im realen Erklingen) ebenso wie Tiara und Gewandung des Pontifex als Insignie der >plenitudo potestatis $<.{ }^{11}$ Zum anderen aber wird im Bildformular neben der Machtrepräsentation besonders deutlich gerade auch das transzendentale Potenzial der Musik als

11 Vielsagend ist hier ein Vergleich etwa zu den Darstellungen König Sigmunds mit den insignia imperialia plus Trompetern und Posaunisten (Konstanz, Rosgartenmuseum Inv. Hs. 1, fol. 38 $39^{\mathrm{r}}$ sowie fol. $74^{\mathrm{v}}$ ) bzw. im Gewand eines Diakons das Weihnachtsevangelium verkündend ebenso von den Reichskleinodien umgeben und nun in Verbindung mit singenden Chorherren (Konstanz, Rosgartenmuseum Inv. Hs. 1, fol. 20v). Wertvolle Deutungsimpulse in diesem Zusammenhang bietet der Band Magnificence and the Sublime in Medieval Aesthetics. Art, Architecture, Literature, Music, hrsg. von C. Stephen Jaeger, New York 2010. 
gleichsam göttliches Medium und Mittlerinstanz zwischen irdischer und himmlischer Sphäre visualisiert: am sinnfälligsten wohl durch die unmittelbare Kombination mit einem weiteren zentralen Symbol für das Übersteigen des Immanenten, den hinter dem Sängerkollegium platzierten, lang aufragenden Kerzen bzw. Kandelabern mit gen Himmel steigenden Flammen und Rauch (was ja auch in Richentals Bericht mehrfach eindrücklich Erwähnung findet). Musik gewinnt eine für den in der Formel »sic transit gloria mundi« gefassten >transitus< hin zur >gloria celestis< essentielle Qualität, dient damit der mystischen Überhöhung und Sakralisierung des Papstes und rückt zugleich - im Sinne einer heilsbringenden Präsenzerfahrung ${ }^{12}-$ in die Nähe zu anderen wichtigen spätmittelalterlichen Medien christologischer Ver-Gegenwärtigung (wie etwa der Heiligenreliquie ${ }^{13}$ oder der 1215 endgültig zum Dogma erhobenen Transsubstantiation ${ }^{14}$ ).

Drittens ist gerade in diesem Zusammenhang auf die exponierte Stellung des Chorbuchs hinzuweisen, das - im Fokus des Bildes, auf der Zentralachse mit dem gekrönten >vicarius Christi< und in dessen direktem Blickfeld - ge-

12 Vgl. hierzu etwa Wolfgang Fuhrmann, Herz und Stimme. Innerlichkeit, Affekt und Gesang im Mittelalter, Kassel u.a. 2004 (Musiksoziologie, 13); sowie den instruktiven Sammelband Medialität des Heils im späten Mittelalter, hrsg. von Carla Dauven-van Knippenberg, Cornelia Herberichs und Christian Kiening, Zürich 2009 (Medienwandel - Medienwechsel - Medienwissen, 10); hierin insbesondere: Christian Kiening, Einleitung, S. 7-20, und René Wetzel, Mystischer Weg und Heilserfahrung. Präsenzkonzepte und -effekte der Engelberger Lesepredigten, S. 279-295.

13 Vgl. etwa Bruno Reudenbach, »Körperteil-Reliquiare. Die Wirklichkeit der Reliquie, der Verismus der Anatomie und die Transzendenz des Heiligenleibes«, in: Zwischen Wort und Bild (wie Anm. 8), S. 11-31. Als wohl prominenteste mittelalterliche Präsenzfigur wurden die Reliquien der Heiligen explizit in der Matrix von spraesentia und svirtus< gefasst. Richental nennt in seinem Rapport zur Papstweihe so eben auch explizit die Büstenreliquiare des hl. Konrad und des hl. Pelagius, den beiden Patronen der Konstanzer Bischofskirche (s.o.). Vgl. zudem die bildliche Darstellung im Exemplar Konstanz, Rosgartenmuseum Inv. Hs. 1, fol. 33 $3^{\mathrm{r}}$ (Büstenreliquiar der durch Johannes XXIII. 1391 kanonisierten Birgitta von Schweden plus päpstliches Sängerkollegium). Die besondere Nähe Birgittas zu (einer göttlich inspirierten) Musik, der eine betont devotionale Funktion beigemessen wird, dürfte in diesem Zusammenhang nicht unwesentlich sein. Vgl. hierzu Klaus Pietschmann, »Kirchenmusikalische Kanonbildung im Kontext mittelalterlicher Heiligkeitskonstruktion«, in: Der Kanon der Musik. Theorie und Geschichte, hrsg. von dems. und Melanie Wald-Fuhrmann, München 2013, S. 199-214.

14 Auch im Bericht wird der Tisch mit Brot und Wein hervorgehoben; s.o. Vgl. auch die Abbildung im Exemplar Konstanz, Rosgartenmuseum Inv. Hs. 1, fol. 100 (Papst Martin V. vor oder während des Canon missae, im Hintergrund die Capella papalis; man beachte auch wieder die Prominenz der Kerzen). Vgl. zum Kontext: Marc-Aeilko Aris, »Quid sumit mus? Präsenz (in) der Eucharistie«, in: Mediale Gegenwärtigkeit, hrsg. von Christian Kiening, Zürich 2007 (Medienwandel - Medienwechsel - Medienwissen, 1), S. 179-192; sowie Burkhard Hasebrink, »Diesseits? Eucharistie bei Meister Eckhart im Kontext der Debatte um »Präsenzkultur«", in: ebda., S. 193-205. 
wissermaßen das Scharnier darstellt, durch das sich der mediale Akt der ssancta imaginatio< vollzieht. Gerade die notationstechnisch fixierte Musik, d.h. ihr Schriftlichkeitsstatus sowie der - bildkompositorisch ebenso deutlich in Szene gesetzte - Lesevorgang durch die Sänger (nicht selten ikonographisch verstärkt auch durch den Bildtypus Augengläser tragender Cantores als Zeichen ihrer Literarisierung ${ }^{15}$ ), also die Sinnesebene des >visus< als Pforte zu Intellekt und Ratio erlangt dabei gesteigerte Bedeutung. Allerdings geschieht dies, ohne dabei die essentielle Instanz des Klanglichen zu ignorieren, die ihrerseits - spätestens seit Johannes de Muris' Einsicht in die wissenschaftstheoretisch-epistemologische Relevanz des Gehörs ${ }^{16}$ - neben dem Gesichtssinn als zentrale Erkenntnisquelle und Urteilsinstanz akzentuiert wird. ${ }^{17}$ Und so wird in der Tat auch der (bildtechnisch ungleich schwerer dingfest zu machende) >auditus< als wesentlicher >sensus< präsentiert, und zwar abgesehen von den geöffneten Mündern nicht wie sonst durch das gängige Motiv eines ostentativ wegschauenden, sich staunend ganz im Hören verlierenden Sängers, ${ }^{18}$ sondern mittels des so auffällig gesichtslosen Kerzenträgers am linken Außenrand, ein im Bildwerk der Richental-Chronik singulärer und irritierender Fall eines offenbar (absichtlich?) nicht zu Ende ausgeführten Bildsegments, bei dem das Ohr freilich umso markanter in den Blick gerät. (Interessanterweise registrierte Richental in seinem Rapport ja auch, dass er trotz langsamen Singens die Musik zwar hörte, nicht aber die Worte verstand, so dass auch hier die rein sinnlichauditive Komponente von Musik jenseits ihrer Relevanz als Text-Vehikel exponiert wird.)

Als weiteres ikonographisch evoziertes Moment von Musik lässt sich neben Akustik und Visualität denn schließlich auch die taktile Wahrnehmungsebene eruieren, nämlich einerseits im Sinne des Haptisch-Materiellen, das über das Festhalten, Berühren und Zeigen der voluminösen Gesangbücher

15 Vgl. etwa Konstanz, Rosgartenmuseum Inv. Hs. 1, fol. $33^{\mathrm{r}}$ und fol. $100^{\mathrm{v}}$.

16 Seit seinen Notitia artis musicae (1321) und seiner Musica speculativa (um 1325) dient das Gehör nicht mehr bloß als Empfangsinstanz der >doctrina<, sondern zugleich auch im Sinne eines Urteils secundum auditum als wissenschaftlich notwendige Sinneserfahrung, die zu (gleichsam empirischen) Erkenntnissen führt.

17 Siehe insgesamt auch Horst Wenzel, »Die Empfängnis durch das Ohr: Zur multisensorischen Wahrnehmung im Mittelalter«, in: Über das Hören: Einem Phänomen auf der Spur, hrsg. von Thomas Vogel, Tübingen 1996, S. 159-179.

18 Vgl. etwa Konstanz, Rosgartenmuseum Inv. Hs. 1, fol. 33 ${ }^{\mathrm{r}}$. Zum Kontext vgl. auch Björn R. Tammen und Frank Hentschel, »Divisio musicae und auditus im frühen 14. Jahrhundert«, in: Artes im Mittelalter, hrsg. von Ursula Schaefer, Berlin 1999, S. 83-109. 
vermittelt scheint, andererseits unter Rekurs auf die gezielt doppelte Bedeutung von >tactus< mit Blick auf die koordinierenden Hände des Priors im Sinne eines gleichsam domestizierten Gestus. Im Verbund mit >visus< und sauditus< scheint so auch dezidiert der taktile, körperlich-physische, gleichsam performative Aspekt von Musik indiziert; und in dieser Hinsicht mag nicht zuletzt noch einmal die auffallende Raumdisposition Beachtung verdienen: Durch die Aufspaltung des Sängerkollegs, mithin die Verortung der Klangquellen in zwei sich gegenüberstehenden Gruppen führt sie dem Betrachter die klangräumliche Dimension von Musik nämlich im Wortsinne >raumhaft< vor Augen. Denn unabhängig davon, ob es sich de facto um einen realen aufführungspraktischen Beleg für das doppelchörig in alternatimPraxis konzipierte Gloria »Jubilatio« des Hubertus de Salinis handelt: ${ }^{19}$ Was durch das bildnerische Arrangement des geteilten Sängerensembles unmittelbar suggeriert und erfahrbar gemacht wird, ist neben dem Verweis auf die performative Interaktion der Cantores (offene vs. geschlossene Münder) das musikalische Ausloten und Durchmessen des >spatium<. Die Reflexion der Raumdimension von Musik tritt neben ihre (einer piktoralen Evokation schwer und gleichsam nur vermittels des Raumes zugängliche) zeitlichtemporale Verfasstheit.

\section{Musik und >plenitudo potestatis in der »Zeit der Zerreißproben«}

Was sich bei einer - auch nur oberflächlichen - Betrachtung der RichentalChronik und ihrer ikonisch sprechenden Bebilderung abzuzeichnen beginnt, nämlich eine kaum zu Eindeutigkeiten neigende spätmittelalterliche Musikauffassung, bei der sich eine Vielzahl an Deutungsspektren und Symbolebenen überlagern, erweist sich dabei gerade in seiner polyvalenten, kaum eingrenzbaren Komplexität insgesamt als überaus geeignet, in Beziehung zur kurialen Macht- und Selbst-Darstellung insbesondere jener heiklen Phase des Papsttums gesetzt zu werden, die treffend als $»$ Zeit der Zerreißproben $\aleph^{20}$

19 Vgl. Strohm, The Rise of European Music (wie Anm. 5), S. 114. Zu diesem Stück siehe unten, S. 132.

20 Die Zeit der Zerreißproben (1274-1449), hrsg. von Bernhard Schimmelpfennig, Freiburg/Br. 1991 (Die Geschichte des Christentums, 6); frz. Original: Un temps d'épreuves (1274-1449), hrsg. von Michel Mollat du Jourdin und Andre Vauchez, Paris 1990. Vgl. auch den noch immer höchst instruktiven Überblick bei Bernhard Schimmelpfennig, Das Papsttum. Von der Antike bis zur Renaissance, Darmstadt ${ }^{6} 2009$; sowie jüngeren Datums: Thomas Frenz, Das Papsttum im Mittelalter, Köln 2010; Michael Basse, Entmachtung und Selbstzerstörung des Papsttums 
charakterisiert werden kann und die zur Entstehungszeit der RichentalChronik ihre Peripetie und ihren Endpunkt erreichte. Die vielfach bekannten Aspekte von und Zugänge zu mittelalterlicher Musik

(1) als prachtvoll-opulentes Repräsentationsmedium bzw. festlich-weihevolles Decorum und zugleich sinnlich wahrnehmbare Vergegenwärtigung von Außersinnlichem und Übernatürlichem bzw. im augustinisch-boethianischen Sinne als Schlüssel bzw. Abglanz der göttlichen Ordnung,

(2) als elitär-intellektuelle Ars und zugleich unmittelbar präsenter, >körperhafter Sinnenreiz,

(3) als verschriftlichtes, konservierungsfähiges Artefakt und zugleich Immateriell-Ephemeres, das untrennbar an seine Realisierung und Darbietung in der Zeit gebunden bleibt,

(4) als genuin spirituelle Praxis und zugleich Anschlussmöglichkeit an höfische sowie philosophisch-humanistische, universitär-gelehrte Diskurse,

(5) als numinos-transzendentes, mystisches Medium verinnerlichter Contemplatio, Devotio und Jenseitsschau, zugleich als eine hochgradig allegorisch-symbolhafte, anagogische, mithin >les<- und deutbare Kunst,

- all dies (und all dies zusammen) prädestinierte Musik in besonderer Weise dazu, ganz essentiell eingebunden zu sein in eine Gesamtinszenierung des Apostolischen Stuhls ${ }^{21}$ gerade zu einer Zeit, in der es - von den avignonesischen Pontifikaten über das Schisma bis hin zum reformkonziliaristischen Machtkampf von Basel / Lausanne und Ferrara / Florenz - vor allem geltungspolitisch um die Durchsetzung, Aufrechterhaltung und Sicherung von stranslatio ecclesiae und Papstprimat ging, nun nicht mehr nur gegen die althergebrachten Widerstände seitens des Kaisers, ${ }^{22}$ der ostkirchlichen Patriarchen und der lokalkirchlichen Bischöfe und Metropoliten, sondern zugleich gegen die massiven Anfechtungen von Avignonkritikern, Gegenpäpsten bzw. Konziliaristen.

Die allseitig zu beobachtenden Bemühungen um Verteidigung und Fortbestand der >plenitudo potestatis< und des damit verbundenen absoluten Anspruchs auf Universalität, wie er etwa in der Bulle Unam Sanctam von Bonifaz VIII. noch einmal nachdrücklich zementiert worden war, schlossen die

(1302-1414), Leipzig 2011 (Kirchengeschichte in Einzeldarstellungen, 2/1); und Klaus Herbers, Geschichte des Papsttums im Mittelalter, Darmstadt 2012.

21 Vgl. zum literaturgeschichtlichen Kontext auch Thomas Haye, Päpste und Poeten. Die mittelalterliche Kurie als Objekt und Förderer panegyrischer Dichtung, Berlin 2009, für den hier betrachteten Zeitraum insbesondere S. 262-284.

22 Vgl. zuletzt Heike Johanna Mierau, Kaiser und Papst im Mittelalter, Köln 2010. 
Musik dabei nicht nur selbstverständlich mit ein, sondern scheinen in ganz zentraler Weise durch sie flankiert. Denn wie kaum eine andere Kunst diente sie einer durchaus spezifisch sakralen Überhöhung des Pontifex; und insbesondere ihre genuinen Qualitäten und Potenziale als zeit- und raumgebundene bzw. Zeit und Raum thematisierende und reflektierende Kunstform ${ }^{23}$ waren es, die sie zum prädestinierten Spiegel und Repräsentanten päpstlichen Selbstverständnisses erhoben - insofern nämlich, als man sie im Sinne einer zeitlichen und räumlichen Allmacht und Souveränität der >maiestas apostolica einerseits sowie einem gottgleichen Verfügen über und Transzendieren von Raum und Zeit andererseits auszuschöpfen trachtete. Sowohl in geistlicher als auch weltlicher Dimension der päpstlichen Machtambitionen vermochte Musik in idealer Weise als Sinnbild und Sinnträger zu dienen in Hinblick auf eine augustinisch gedachte Allpräsenz und Raumlosigkeit Gottes sowie Raumgebundenheit der Schöpfung zum einen und in Hinblick auf eine zeitaufhebende Ewigkeit Gottes sowie eine sinnvolle Gestaltbarkeit der irdischen Temporalität zum anderen; das Einnehmen sowie das Übersteigen von Raum scheint in Musik ebenso indizier- und verhandelbar wie

$23 \mathrm{Zu}$ den noch nicht erschöpfend erforschten Zeit- und Raumkonzepten mittelalterlicher Musik vgl. aus der gleichwohl großen Anzahl an Literatur Michael Walter, Grundlagen der Musik des Mittelalters. Schrift - Zeit - Raum, Stuttgart 1994; Anne Stone, Writing Rhythm in Late Medieval Italy. Notation and Style in the Manuscript Modena, Biblioteca Estense, Alpha M.5.24, PhD Diss. Harvard Univ. 1994; Norman Carey und David Clampitt, »Regions: A theory of tonal spaces in early medieval treatises«, in: Journal of music theory 40 (1996), S. 113-147; Klaus Wolfgang Niemöller, »Weltraum-Musik und Klangraum im mittelalterlichen Musikschrifttum «, in: Raum und Raumvorstellungen im Mittelalter, hrsg. von Jan A. Aertsen und Andreas Speer, Berlin und New York 1997 (Miscellanea mediaevalia, 25), S. 702-725; Laurenz Lütteken, »Zeitenwende. Zeit und Zeitwahrnehmung in der Musik des Spätmittelalters«, in: Neue Zeitschrift fiur Musik 160 (1999), S. 16-21; Dorit Tanay, Noting Music, Marking Culture. The Intellectual Context of Rhythmic Notation, 1250-1400, Holzgerlingen 1999 (Musicological Studies and Documents, 46); Michael Eisenberg, »The mirror of the text. Reflections in $>$ Ma fin est mon commencement «, in: Canons and canonic techniques, 14th-16th centuries. Theory, practice, and reception history, hrsg. von Katelijne Schiltz und Bonnie J. Blackburn, Leuven 2007 (Analysis in context. Leuven studies in musicology, 1), S. 83-110; Klaus Pietschmann, »Zeit und Ewigkeit. Zum liturgischen Kontext der Gradual- und Alleluia-Gesänge im ^Magnus Liber Organi«, in: Archiv für Musikwissenschaft 66 (2009), S. 54-68; sowie Pascale Duhamel, Polyphonie parisienne et architecture an temps de l'art gothique (1140-1240), Bern 2010; Dorit Tanay, »Time and money: A new look at the mathematical foundation of the Ars Nova «, in: Tijdschrift for muziektheorie 15 (2010), S. 18-31; Signe Rotter-Broman, »The manifestation of musical time in Italian ballatas around 1400: The case of Andrea da Firenze's Non più doglie ebbe Dido«, in: Plainsong and medieval music 19 (2010), S. 123-137; Vasco Zara, »Architektur und Musik. Literarische Metaphern und kompositorische Prozesse «, in: Musica. Geistliche und weltliche Musik des Mittelalters, hrsg. von Vera Minazzi, Freiburg/Br. u.a. 2011, S. $244 f$. 
ein eher diffuser, heteronom definierter »temps de l'église« und ein präzise mess-, kalkulier- und planbarer $\gg$ temps du marchand $« .{ }^{24}$

\section{Raum-Zeit-Kunst zwischen Hermeneutik und Präsenz}

Wie vielfältig und variantenreich das musikspezifische Potenzial als Raumund Zeitkunst im Einzelnen konkret zugunsten des Anspruchs auf die splenitudo potestatis`vereinnahmt werden konnte, lässt sich freilich ebenso wenig an Textdokumenten ${ }^{25}$ wie an Bildzeugnissen ablesen, so plastisch diese auch sein mögen. Aufschluss geben kann hier letztlich allein eine Autopsie der entsprechenden musikalischen Quellen selbst. Im Folgenden soll daher mit Blick auf einige exemplarische papstbezogene Kompositionen der Zeit zwischen Philippe de Vitry und Guillaume Dufay ${ }^{26}$ aufgespürt werden, welche Strategien, Verfahren und Mechanismen in concreto dazu dienen konnten, im Medium der Musik Raum- und Zeitkonzepte ins Werk zu setzen und diese mit den Zielen pontifikaler Legitimation, Machtsicherung und Panegyrik zu profilieren. Insgesamt gilt es dabei in Hinsicht auf Rezep-

24 Jacques LeGoff, »Temps de l'église et temps du marchand«, in: Annales 15 (1960), S. 417-433. Zum mittelalterlichen Zeit- und Raumbegriff existiert eine Fülle an Literatur. Als Einführung noch immer grundlegend: Aaron J. Gurjewitsch, Das Weltbild des mittelalterlichen Menschen, München ${ }^{5} 1997$ (Beck's historische Bibliothek). Pars pro toto seien ferner genannt: Zeitkonzeptionen - Zeiterfahrung - Zeitmessung. Stationen ihres Wandels vom Mittelalter bis zur Moderne, hrsg. von Trude Ehlert, Paderborn u.a. 1997; Raum und Raumvorstellungen im Mittelalter (wie Anm. 23); Virtuelle Räume. Raumwahrnehmung und Raumvorstellung im Mittelalter, hrsg. von Elisabeth Vavra, Berlin 2005; Imaginäre Räume. Sektion B des internationalen Kongresses »Virtuelle Räume. Raumwahrnehmung und Raumvorstellung im Mittelalter«, hrsg. von ders., Wien 2007. Gute Orientierung in Hinblick auf Bedeutung von Raum und Zeit im theologischen Kontext des Mittelalters bieten: Manfred Stöckler u.a., »Raum«, in: Lexikon für Theologie und Kirche, hrsg. von Walter Kasper, Freiburg/Br. ${ }^{3} 2006$, Bd. 8, Sp. 853-856; Joachim Klose u.a., »Zeit / Zeitlichkeit«, in: ebda., Bd. 10, Sp. 1404-1413; Andreas Hüttemann und Luco Johan van den Brom, »Raum«, in: Religion in Geschichte und Gegenwart, hrsg. von Hans Dieter Betz, Tübingen ${ }^{4} 2008$, Bd. 7, Sp. 62-65; Jürgen Mohr u.a., »Zeit / Zeitvorstellungen«, in: ebda., Bd. 8, Sp. 1800-1819; Wolfgang Breidert, »Raum«, in: Lexikon des Mittelalters, hrsg. von Norbert Angermann u.a., Darmstadt 2009, Bd. 7, Sp. 478f.; Rolf Sprandel, »Zeit«, in: ebda., Bd. 9, Sp. 509-513.

25 Diese hüllen sich eben weitgehend in (vielsagendes?) Schweigen; vgl. Anm. 7.

26 Einen ersten Überblick über das herangezogene Repertoire bietet Margaret Bent, »Early Papal Motets«, in: Papal Music and Musicians in Late Medieval and Renaissance Rome, hrsg. von Richard Sherr, Oxford 1998, S. 5-43. Vgl. auch: Giuliano di Bacco und John Nádas, »The Papal Chapels and Italian Sources of Polyphony During the Great Schism», in: ebda., S. 44-92. Siehe insgesamt zudem: Pamela F. Starr, $»$ Rome as the centre of the universe. Papal grace and music patronage«, in: Early Music History 11 (1992), S. 223-262. 
tions- und Verstehensbegriffe des Mittelalters sowie eine zu präsupponierende $>$ Medienkompetenz< der spätmittelalterlichen Adressaten ${ }^{27} \mathrm{zu}$ ergründen, wie auf den verschiedenen, zunächst einmal systematisch getrennt zu betrachtenden Sinnes-, Wahrnehmungs- und Verstehensebenen - dem wortsprachlichen Text, der musikalischen Struktur, dem auditiven Klangeindruck und der performativen Realisierung sowie der visuellen Ebene des Musiklesens bzw. »hearing with the eyes $\ll^{28}$ - Bedeutung generiert wird und wie sich die einzelnen Komponenten und Zugänge im Sinne eines fortschreitenden, sukzessive sich vertiefenden Eindenkungsvorgangs und Erkenntnisweges (wie ihn folgenreich etwa Bonaventuras Itinerarium mentis in Deum formuliert hatte) koppeln und vor dem Horizont der Vorstellung vom vielfachen >sensus scripturae $<$ zusammenfügen. $»$ Nihil enim visibilium rerum corporaliumque est, ut arbitror, quod non incorporale quid et intelligibile significet ${ }^{29}{ }^{29}$ hatte bereits Johannes Scotus Eriugena bekannt und damit auf den symbolhaften Zeichencharakter aller sich gegenseitig befruchtender Sinneserfahrungen und Wahrnehmungsbereiche verwiesen, dem gegenüber man im Zuge der Nominalismusdebatten des 13. und 14. Jahrhunderts noch einmal gesteigerte Sensibilität zukommen ließ; oder mit den Begrifflichkeiten des vorliegenden Tagungsbandes formuliert: Musikalische Performanz im Spätmittelalter ereignet sich auf ganz verschiedenen medialen Ebenen,

27 Vgl. aus der Fülle neuerer Literatur: Werner Faulstich, Medien und Öffentlichkeiten im Mittelalter 800-1400, Göttingen 1996 (Die Geschichte der Medien, 2); Medien der Kommunikation im Mittelalter, hrsg. von Karl-Heinz Spieß, Stuttgart 2003 (Beiträge zur Kommunikationsgeschichte, 15); Martin Andree, Archäologie der Medienwirkung. Faszinationstypen von der Antike bis heute, München 2005; Moos, Rhetorik, Kommunikation und Medialität (wie Anm. 10); David Ganz, Medien der Offenbarung. Visionsdarstellungen im Mittelalter, Berlin 2008; Modelle des Medialen im Mittelalter, hrsg. von Christian Kiening und Martina Stercken, Berlin 2010 (Das Mittelalter, 15/2); Zwischen Wort und Bild. Wahrnehmungen und Deutungen im Mittelalter (wie Anm. 8); Afra Reinl, Lebensformung durch Medien im Mittelalter, Berlin 2011 (Reform und Innovation, 17).

28 Christle Collins Judd, Reading Renaissance Music Theory. Hearing with the Eyes, Cambridge 2000 (Cambridge Studies in Music Theory and Analysis). Dort insbesondere für das 16. Jahrhundert in Anschlag gebracht, lässt sich die Formel freilich treffend auch für die musikalische Schriftlichkeitskultur um 1400 verwenden. Vgl. Olivier Cullin, L'image musique, Paris 2006; sowie jüngst The Calligraphy of Medieval Music, hrsg. von John Haines, Turnhout 2011 (Musicalia Medii Aevi, 1).

29 »Ich glaube, dass es nichts Sichtbares und Körperliches gibt, was nicht etwas Unkörperliches und Intelligibles bedeutet«. Johannes Scotus Eriugena, De divisione naturae V,3, PL 122, c. 865f., hier zitiert nach: Umberto Eco, Kunst und Schönheit im Mittelalter, München und Wien 1991, S. 90. Vgl. insgesamt auch Henri de Lubac, Typologie, Allegorie, geistiger Sinn - Studien zur Geschichte der christlichen Schriftauslegung, Freiburg 1999 (Theologia Romanica, 23). 
die jede für sich, vor allem aber in ihrer wechselseitigen Überlagerung und Ergänzung immer auch als Sinnträger für etwas anderes, hier speziell in Hinblick auf die päpstliche Repräsentation (und darüber hinaus auf ein Höheres, Göttliches) fungiert. ${ }^{30}$

Als gleichsam propädeutische Grundüberzeugung steht dabei im Hintergrund, dass die Aspekte der von Hans Ulrich Gumbrecht namhaft gemachten »Präsenzkultur « des Mittelalters ${ }^{31}$ in der Musikforschung trotz der durch Christopher Page bereits in den 1990er Jahren ausgelösten Debatten ${ }^{32}$ zwar bis dato nicht die Aufmerksamkeit beanspruchen, die sie verdienen mögen, dass die für die Wirkmechanismen des Mediums Musik durchaus essentielle Ebene des Gegenwärtig-Präsentischen dabei mitnichten aber allein »diesseits der Hermeneutik « zu lokalisieren ist, sondern dass ihr stets ganz wesentlich Momente der verstandesmäßigen Auslegung und Durchdringung gleichsam inhärent sind. Insbesondere für die epistemologisch krisenhafte Sattelzeit um 1400 scheint dabei zu gelten, dass der permanente Decodierungsvorgang von Signifikanten im spätmittelalterlichen Weltzugang gewissermaßen erst die unmittelbare Präsenz des Signifikats erwirkt; ${ }^{33}$ hermeneutischexegetischer Akt und Erzeugung von Präsenz, diskursive Entfaltung und performative Vergegenwärtigung greifen in einander; »Präsenzkultur « und »Sinnkultur « bedingen sich wechselseitig. Und nur in dieser - im Einzelfall durchaus unterschiedlich akzentuierbaren - Reziprozität werden die päpstlichen Ambitionen auf Sicherung ihrer Führungsposition durch Evozierung zeitlich-räumlicher Souveränität, wie sie sich als ein erstaunlich konstanter, sozusagen sinnstiftender Fluchtpunkt papstpanegyrischer Kompositionen in den knapp hundert Jahren zwischen Clemens VI. und Eugen IV. manifestieren, vollständig greifbar. (Inwiefern sich möglicherweise gerade hier im Verhältnis von musikalischer Präsenz- und Sinnkultur die entscheidenden wahrnehmungsbezogenen Gefügeverschiebungen ereignen, aufgrund derer

30 Vgl. die einleitenden Überlegungen von Klaus Pietschmann in diesem Band.

31 Hans Ulrich Gumbrecht, Diesseits der Hermeneutik. Die Produktion von Prösenz, Frankfurt am Main 2004, insbesondere S. 98-110.

32 Die fruchtbare Debatte ging aus von dem (an sich durchaus nicht unproblematischen) Ansatz bei Christopher Page, Discarding Images: Reflections on Music and Culture in Medieval France, Oxford 1993.

33 Vgl. auch: Knowledge through signs. Ancient semiotic theories and practices, hrsg. von Giovanni Manetti, Turnhout 1996 (Semiotic and Cognitive Studies, 2); William T. Flynn, Medieval Music as Medieval Exegesis, Lanham 1999 (Studies in Liturgical Musicology, 8); sowie Literarische und religiöse Kommunikation in Mittelalter und Früher Neuzeit, hrsg. von Peter Strohschneider, Berlin 2009. 
sich ab der Mitte des 15. Jahrhunderts dann ein offensichtlich grundlegender Wandel in der päpstlichen Funktionalisierung von Musik vollzieht, wird zu diskutieren sein.)

Dass sich eine Zeit-Raum-bezogene musikalische Huldigung des Pontifex dabei zunächst im Grunde ausschließlich im gelehrt-elitären Rahmen päpstlicher >musica reservata< eruieren lässt, ${ }^{34}$ ehe sich erst gegen Ende des Schismas Kompositionen mit explizitem Papstbezug ausmachen lassen, die derartige Strategien nun auch nachweislich im Kontext liturgischer (stärker auf Unmittelbarkeit und Wirkmacht bedachter) Zeremonien erproben, bevor elaboriertere musikalische Raum- und Zeitkonzepte dann mit Guillaume Dufay schließlich vollständig in die rituelle Umgebung des Papstgottesdienstes überführt und implementiert zu werden scheinen, ist ein bemerkenswerter Prozess, der im Hintergrund der nachfolgenden Betrachtungen als historiographischer Befund stets mitzubedenken ist. Denn er markiert im Grunde eine ebenso latente wie nachhaltige Gewichtsverlagerung vom eher Intellektualistisch-Hermeneutischen zum stärker Effekthaft-Präsentischen und Inszenatorisch-Performativen - so wie hier jeweils in unterschiedlichem Maße zugleich Spannungsfelder zu wirken scheinen, wie sie aus dem Miteinander und Gegenüber der von Nikolaus Staubach namhaft gemachten Assimilations-, Distinktions- und Partizipationsmodelle päpstlicher Repräsentation zwischen Tugendhaftigkeit, Imposanz und Solidarisierung resultieren. ${ }^{35}$

\section{Raum-Zeit-Souveränität, ımusica mensurabilis` und ınumerositas`}

Verweise auf Raum und Zeit stehen dabei in der Tat bereits Mitte des 14. Jahrhunderts im Fokus von Philippe de Vitrys Huldigungsmotette Petre clemens $\mid$ Lugentium | Non est inventus ${ }^{36}$ für Clemens VI., also jenen Pontifex, der - vormals Kanzler König Philips VI. - nicht nur insgesamt durch seine Selbstverherrlichung, seine luxuriöse Hofhaltung und die Zunahme an zeremoniellem Aufwand bekannt ist, sondern mit dem Ankauf der Grafschaft Avignon und der Errichtung eines Kirchenstaates an der Rhône sowie

34 Ausnahmecharakter scheint hier allein dem anonymen Gloria »Clemens deus artifex« zuzukommen. Die Frage nach der Verwendung von Motetten ist freilich stets eine problembeladene, ob im profanen oder sakralen Bereich. Insbesondere für das hier betrachtete Repertoire müssen die konkreten Aufführungskontexte hypothetisch bleiben. Bedenkenswerte Vorschläge und Hinweise bei Bent, »Early Papal Motets« (wie Anm. 26), die insgesamt den »use as edifying and politically charged chamber music in private and semiprivate contexts« betont (S. 39).

35 Vgl. den Beitrag von Nikolaus Staubach im vorliegenden Band.

36 Überliefert in: Codex Ivrea, fol. $37^{\mathrm{v}}-38^{\mathrm{r}}$; Edition in: PMFC I, S. 97-103. 
mit dem Ausbau des Papstpalastes um einen weiteren Wohnturm, einen verlängerten Westflügel und einen neuen Trakt mit zweiter Kapelle und Audienzhalle ganz speziell ein gesteigertes Bewusstsein für die geographischen und architektonischen Dimensionen seiner Macht, kurz: für Fragen der Raumerschließung und -gestaltung zu erkennen gibt (ganz zu schweigen von der gezielten fiskalischen Erfassung der Gesamtkirche). ${ }^{37}$ Die 1344 in Angriff genommene Reformierung des Kalenders auf Basis einer neuen arithmetischen Terminierung des >numerus aureus< (Datierung des Osterfestes), zu der unter anderem Johannes de Muris herangezogen wurde, dokumentiert parallel hierzu ein spezielles Sensorium für Phänomene der Zeitmessung, -erfassung und -gestaltung, was im größeren Kontext der zeitgenössischen, innovativ auf Aristoteles' Zeitaporie zurückgreifenden Debatten und Theorien (von Aegidius Romanus bis hin zu Johannes von Jandum, Wilhelm von Ockham und Johannes Buridanus) als Reflex eines neuartigen Verständnisses von Zeit als physikalisch-naturphilosophisch bestimmbarer, kontinuierlicher, beliebig oft teilbarer Entität verstanden werden kann. ${ }^{38}$

Vor allem aber ist es der unmittelbare Entstehungskontext, der die Ausrichtung der Motette einsichtig macht: Anlass nämlich war der Empfang einer römischen Delegation zum Jahreswechsel 1342/1343, die Clemens wie seit Nikolaus III. Usus - zum Senator von Rom proklamierte und ihn zur Rückverlagerung des Heiligen Stuhls an den Tiber bewegen wollte eine Bitte, die Clemens unter Verweis auf das seit dem 13. Jahrhundert bekannte Diktum »ubi Papa, ibi Roma «99 ausschlug, während er dem zweiten Anliegen der Gesandtschaft, 1350 ein Heiliges Jahr anzuberaumen, bezeichnenderweise nachkam, womit er die Weisung Bonifaz' VIII., nur alle hundert Jahre ein Jubeljahr auszurufen, gezielt außer Kraft setzte. Was sich in beiden Entscheidungen niederschlägt, ist also Clemens' Wille, sich als Souverän über Raum und Zeit zu positionieren bzw. diesbezügliche Belange

37 Siehe Diana Wood, Clement VI: The Pontificate and Ideas of an Avignon Pope, Cambridge 1989; zur Rolle der Musik in seinem Umfeld vgl. auch die entsprechenden Abschnitte in Andrew Tomasello, Music and Ritual at Papal Avignon 1309-1403, Ann Arbor 1983 (Studies in Musicology, 75).

38 Vgl. mit Blick auf die Problemstellungen der smusica mensurabilis` etwa Fabrizio Della Seta, »Utrum musica tempore mensuretur continuo, an discreto. Premesse filosofiche ad una controversia del gusto musicale«, in: Studi musicali 13 (1984), S. 169-219.

39 Vollständig lautet die Formel: »Ubi est ergo summus Episcopus, qualis est Papa, ibi est Romana Ecclesia, ibi est Sedes apostolica.«Vgl. Stephanus Baluzius, Vitae Paparum Avenionensium, hrsg. von Guillaume Mollat, 4 Bde., Paris ${ }^{2} 1914-1922$, Bd. I, S. xiii. 
ostentativ in seiner Verfügungsgewalt zu halten. Und exakt dieses Bedürfnis scheint auch Vitrys Motette mit all ihren medialen Möglichkeiten zu reflektieren.

So ist der Tenor »Non est inventus«, der die Unvergleichbarkeit und Singularität des Widmungsträgers verbalisiert, dem Graduale Ecce sacerdos magnus entnommen ${ }^{40}$ und lenkt den Blick somit innerhalb eines textlichen Verweissystems auf die sogenannte Konstantinische Schenkung und die Etablierung päpstlicher Macht unter Papst Silvester, also letztlich auf Clemens' Verhältnis zur Ostkirche. Entsprechend kreisen die Huldigungstexte von Triplum und Motetus um allegorische Reflexionen auf Silvester und Clemens und stellen unter Verwendung allgemeiner Raumbegriffe wie $» y m o$ et supremo«, »orbis deditus «, »princeps orbis, sed orbis languidi«, »mudiales celis«, »urbs« und »orbi perutilis« sowie zahlreicher präziserer geographischer Angaben wie »Thaneaos«, »Turcorum«, »Mempheos«, »Armenia «, »Ismael«, »Syris«, »Indis«, »Athlanticis et Ethiopibus«, »Stiris«, »Syria « und »Israel« Bezüge zum Kampf des Kirchenoberhauptes gegen die Häretiker her. Indem sie zudem gleichnishaft den mythisch-antiken Konflikt zwischen Tyestes und Atreus sowie den Disput zwischen den Söhnen Philipps V. von Mazedonien (»Absit tuo Tyestes tempore et Athreus, absint Thebaides abutentes fraterno iecore; unumque sint scissi Philipides «) nennen, rücken sie die Raumfragen dabei nicht nur in größere (über-)zeitlich-historische Dimensionen, sondern exponieren zugleich dezidiert Clemens' machtpolitische Relevanz, insofern als hier konkretere Allusionen evoziert scheinen, etwa Clemens' Rolle im Krieg zwischen England und Frankreich sowie vor allem seine ambitiösen Verhandlungen um die Kirchenunion mit Zentralort Avignon.

Im Motetus wird dieser Bedeutungshorizont signifikanterweise durch die Dimensionen des jetzt ganz expliziten zeitlichen Verweises »Non augentur memento secula, non inane tumescunt guttula« konturiert, was im Verbund mit den mythisch-historischen Bezugsfolien der Texte nun in der Tat in Richtung einer gezielten Approbation päpstlicher Überzeitlichkeit zu werten wäre. Denn nicht zuletzt der Rückgriff auf eine speziell musikbezogene Metaphorik (»ac dum flectis sermonis timpanum corda rapis ad auris organum«) lässt Clemens insgesamt zu einem raum- und zeitsouveränen Harmoniestifter im Sinne von >musica coelestis $<$ und >musica mundana $<$ stilisiert erscheinen, wobei die Nennung von >timpanum<, >corda $<$ und >organum $<$ vor

40 Vgl. Alice Clark, »New tenor sources for fourteenth-century motets«, in: Plainsong and Medieval Music 8 (1999), S. 107-131, zu Petre clemens speziell: S. 116-121. 
dem Horizont der mittelalterlich-exegetischen Instrumenten-Symbolik nicht nur allgemein im Kontext von sharmonia<, >concordia $<$ und >laudatio Dei< zu deuten wäre, sondern durchaus auch konkreter in Richtung einer christusgleichen Transzendierung des Körperhaft-Leiblichen, Raum- und Zeitgebundenen (>mortificatio carnis< - >vivificatio spiritus<) bzw. im Sinne der prophetisch-apostolischen Qualitäten des Pontifex. ${ }^{41}$

In der musikalischen Faktur steht der nachdrücklichen wortsprachlichen Ausrichtung auf derartige Dimensionen jedenfalls zum einen der Befund gegenüber, dass der Tenor nach dem Introitus zwar getreu die ersten sechs Töne der Choralmelodie aufgreift - man beachte die Reverenz an Clemens VI. sowie die allgemein hohe Symbolträchtigkeit der Sechszahl als erste und vollkommenste der sogenannten $>$ numeri perfecti ${ }^{42}$-, sich sodann allerdings nur mehr vage des >cantus prius factus< als freie Inspirationsquelle bedient. ${ }^{43}$ Stattdessen scheint der Tenor in der Tat primär darauf ausgerichtet, immer neu in ausladendem Ambitus gezielt den Tonraum auszumessen: signifikanterweise auch hier zunächst immer wieder im Umfange just einer Sext, die mit Blick auf ein guidonisches Hexachordverständnis durchaus auch für die Idee von Universalität und Umfassendheit einstehen mag, dann schließlich bis hin zur Oktav, die im Tonsystem des Mittelalters eben nicht einfach Verdoppelung des unteren Tones meinte, sondern als sdiapason< zugleich

41 Zur mittelalterlichen Instrumenten-Metaphorik noch immer grundlegend ist Helmut Giesel, Studien zur Symbolik der Musikinstrumente im Schrifttum der alten und mittelalterlichen Kirche (von den Anfängen bis zum 13. Jahrbundert), Regensburg 1978 (Kölner Beiträge zur Musikforschung, 94).

42 Abgesehen davon, dass das Christusmonogramm aus Chi und Rho sechsarmig ist, wird die Sechs - aufbauend auf Boethius, Ambrosius, Augustinus und Gregor - im System mittelalterlicher significationes numerorum< einerseits als Verdoppelung der >Trinitätszahl begriffen, andererseits - im Sinne von Vollkommenheit - zugleich als Summe und Produkt der in Drei enthaltenen ganzen Zahlen, sodann auch als Zahl Christi als Verbindung von Gottheit (Eins) und Mensch (Fünf), schließlich - da Sechs zugleich die letzte Ziffer ihres Quadrats 36 ausmacht und dabei auch auf die $360^{\circ}$ des Kreises verweist - als zirkuläre Zahl, die damit wiederum auf Vollkommenheit und Unendlichkeit deutet. In diesem Sinne hatte bereits Augustinus in De civitate Dei formuliert, dass die Schöpfung wegen der Vollkommenheit am sechsten Tage vollendet worden sei. Vgl. zur mittelalterlichen Zahlensymbolik: Hans A. Hutmacher, Symbolik der biblischen Zablen und Zeiten, Paderborn 1993; Heinz Meyer und Rudolf Suntrup, Lexikon der mittelalterlichen Zablenbedeutungen, München 1999; sowie Annemarie Schimmel, Numbers. An Overview, in: Encyclopedia of Religion, 2. Auflage, hrsg. von Lindsay Jones, Bd. 10, Detroit u.a. 2005 , S. $6745-6751$.

43 Das Procedere, ausgehend vom Anfangsgestus eines choralgebundenen Tenors eine neue Melodie zu entwickeln, ist sonst allenfalls aus Machauts Tous corps qui de bien amer | De souspirant cuer dolent | T. Suspiro bekannt. 
den gesamten Tonbestand der vier plus vier Modi sowie das gesamte melodische und klangliche Potenzial, das darin gewissermaßen allerschöpfend angelegt ist. ${ }^{44}$ (Nur erinnert sei im Übrigen daran, dass Intervalle, die seit Boethius, der Musica enchiriadis und Aurelianus Reomensis stets in Begriffen wie »distantia«, »diastema« oder »spatium «, also explizit räumlich gefasst wurden, nach 1300 verstärkt zu einem naturphilosophisch-physikalischsinnlichen Gegenstand im Sinne einer >scientia media< wurden. ${ }^{45}$ )

Was sich jenseits eines lesenden Zugangs, der die >numerositas der Struktur ergründet und eine entsprechende Zahlenallegorese betreibt, zugleich durchaus dem Urteil >secundum auditum<, also dem rein hörenden Rezipienten erschließt, nämlich der außergewöhnliche Ambitus des Tenors, wird durch weitere nicht zuletzt deutlich auditiv wahrnehmbare Signale ergänzt: So erweist sich der Tenor rhythmisch entgegen dem Usus isorhythmischer Fakturen erstaunlich eng am Gepräge der Oberstimmen orientiert und hat insbesondere auch an den markanten Hoquetus-Passagen nahezu gleichberechtigt Anteil. ${ }^{46}$ Was man ebenso räumlich als Annäherung zulasten der herkömmlichen, im merklich kanonisch gefassten Introitus noch deutlich etablierten Dichotomie Triplum + Motetus vs. Tenor zugunsten einer immer größeren Einheit des Duktus werten mag - Gedanken an Einheit und Universalität der päpstlichen Kirche drängen sich auf -, wird dabei ergänzt durch ebenso sinnfällige (besonders in der jeweiligen performativen Darbietung sich manifestierende) temporale Aspekte. Nicht nur nämlich handelt es sich bei Petre clemens um die längste erhaltene Motette Vitrys; vielmehr ist sie mittels herausstechender Ähnlichkeiten des Oberstimmensatzes am Beginn einer jeden Talea auf der Ebene des Color durch eine Art latente strophenförmige Repetitionsstruktur geprägt. Dass diese immanent kreisförmige Anlage im Sinne steter Wiederholung und Perpetuierung in Hinblick auf Konzepte wie Ewigkeit und zeitliche Universalität zu deuten

$44 »$ In quibus octo tonis non solum omnis harmonia spiritualis melodiae, verum etiam omnis naturalis cantilena continetur, atque comprehenditur«, heißt es bereits bei Regino von Prüm in seiner Epistola de harmonica institutione. Neben den Aspekten musikalischer Einheit und Allumfassendheit weist die Acht im biblischen Kontext freilich um eins über die Zahl der Schöpfungstage hinaus und deutet somit auf die mit der Auferstehung Christi begonnene neue Zeit. Auch in diesem Sinne also mögen entsprechende Deutungen in Richtung einer Legitimierung der päpstlichen Vormachtstellung impliziert sein.

45 Vgl. etwa Frank Hentschel, Sinnlichkeit und Vernunft in der mittelalterlichen Musiktheorie. Strategien der Konsonanzwertung und der Gegenstand der musica sonora um 1300, Stuttgart 2000 (Beihefte zum Archiv für Musikwissenschaft, 47).

46 Vgl. auch Joanna Richards, A Study in Coherence in Four Motets by Philippe de Vitry, M.A.-Thesis Univ. of Wales, Bangor 1995, S. $65 \mathrm{ff}$. 
wäre, liegt auf der Hand, zumal sie subtil gekoppelt ist an eine Vielzahl vertrackter, im Detail wohl nur dem kennerschaftlichen Leser sich erschließender rhythmischer Finessen der $>$ musica mensurabilis $<,{ }^{47}$ deren philosophischsinntragende, primär Zeitkonzepte betreffende Konnotationen offenkundig waren (und zwar gerade über solche mit Clemens und Vitry gleichermaßen in Kontakt stehende Exponenten wie Johannes de Muris).

Eine solche Lesart erlangt dabei jedenfalls insofern umso größere Plausibilität, als auch in der musikalischen Zeitgestaltung wieder deutlich Prinzipien der >significationes numerorum< zugrunde liegen: So ist der Tenor insgesamt aus $6^{3}=216$ Tönen gebildet, eine jede Talea besteht aus 33 Breven, Talea I beginnt vor der Hoquetus-Partie mit sechs Breven usw., wobei der Vollkommenheit indizierenden Sechszahl als >numerus perfectus stets die heilige Siebenzahl als Umfassendheit signalisierender >numerus Creatoris et creaturae ${ }^{48}$ zur Seite steht, so dass zugleich nun auch die sieben Buchstaben des Namens Clemens in die musikalische Struktur überführt scheinen. (Der komplette Papstname Clemens VI. ist hier also durch die Sechs- und Siebenzahl in der Faktur der Motette implementiert und damit zugleich in Richtung einer päpstlichen Raum-Zeit-Souveränität ausgelegt.) Denn nicht nur umfasst das mit sechs plus sechs Tenortönen bestrittene Exordium sieben Longen und die Motette besteht aus sieben Taleae, sondern auch die Schlusslonga ist über die Dauer von sieben Breven zu halten. Huldigungsreferenzen auf Persona und Namen des Papstes sowie die Hypostasierung von dessen allumfassender, raum- und zeitumspannender Potenz verschrän-

47 Die Strategie, mittels exzeptioneller Rhythmisierung und durch ein komplexes Temporalgefuige auf Primat und zeitliche Souveränität des Papstes zu verweisen, scheint bereits in Motetten für Johannes XXII. Usus: Das anonyme Per grama protho paret | Valde honoratus est beatus Johannes bedient sich ebenso einer diffizilen Rhythmisierung mit außergewöhnlichen Gruppierungen, Pausen und Hoquetus-Passagen (inklusive der bis dato noch unüblichen Notwendigkeit der Minima-Halsung) sowie einer neuartigen isorhythmischen Durchgestaltung von Tenor und (annähernd auch) Motetus wie das Vitry zugeschriebene Flos ortus | Celsa cedrus | Quam magnus pontifex, bei dem die Überlappung von Color und Talea mit zwei Colores über dreieinhalb Taleae nicht weniger avanciert scheint als die Wiederholung in Diminution.

48 Als Summe aus göttlicher Trinität und irdischen Elementen meint die Sieben himmlische und weltliche Universalität. Auch als biblische Zahl deutet sie über Schöpfungswoche, Erzengel, Gaben des Heiligen Geistes, Seligkeiten der Bergpredigt, Bitten des Vaterunser, Sakramente, Grade der Priesterweihe, Tugenden und Todsünden, Siegeln der göttlichen Ratschlüsse über die Zukunft usw. auf Totalität. Im profanen Bereich stehen dem die Himmelssphären, die Planeten Jupiter, Merkur, Saturn, Sol, Venus, Mars und Luna, die Wochentage, die Artes liberales etc. zur Seite. Vgl. neben der in Anm. 42 genannten Literatur zuletzt auch Reinhard Schlüter, Sieben. Eine magische Zahl, München 2011. 
ken sich über einem hochkomplexen Beziehungsgeflecht implikationsreicher zahlenbasierter Strukturen und Gestaltungselemente.

\section{Universalepiskopat, ımediator«-Funktion, graphisches Notat und Visualisierung}

Was sich bei Vitry um die Jahrhundertmitte dergestalt abzuzeichnen beginnt, nämlich der textlich-musikalische Doppelverweis auf die räumliche und zeitliche Souveränität des gefeierten Papstes, findet sich fortgesetzt in der Papst Gregor XI. gewidmeten, ${ }^{49}$ auf Mitte der 1370er Jahre zu datierenden Diminutionsmotette Pictagore per dogmata | O terra sancta | Rosa vernans, die als anonymes Unicum im Codex Chantilly erhalten ist (siehe Abbildung 3a), ${ }^{50}$ also in jener zentralen Quelle der Umbruchsdekaden um 1400, in der die selbstreferenzielle Reflexion und Verhandlung von (nicht nur) Zeit- und Raumdimensionen der Musik und des Musizierens ganz wesentlich den spezifischen Sinn- und Deutungshorizont bestimmt. ${ }^{51}$

Dass gerade im Umfeld des Papsttums insbesondere Raumfragen während der mit Petrarca vielfach als >babylonisches Exil bezeichneten avignonesischen Residenzzeit zunehmende Virulenz erlangten, scheint dabei naheliegend. Man denke nur an die Nachbildung des auf Gregor I. zurückreichenden stadtrömischen Stationskirchensystems im Avignoner Papstpalast und die damit vollzogene Substitution bzw. Quasi-Integration einer dezidiert urbanen liturgischen Praxis in ein immer stärker privat-exklusives Palastzeremoniell ${ }^{52}$ oder auch an die aktuelle missionspolitische Dimension, hatte die Kurie doch jenseits von Byzanz, dem man sich allmählich anzunähern vermochte, im letzten Drittel des Jahrhunderts durchaus schwere Ein-

49 Zur Musikpflege dieses Papstes: Tomasello, Music and Ritual at Papal Avignon (wie Anm. 37).

50 Codex Chantilly, fol. 63 $-64^{\mathrm{r}}$; Edition in: CMM 390, S. 33-39.

51 Vgl. A Late Medieval Songbook and Its Context (wie Anm. 3).

52 Hatte Benedikts XII. Kapelle den Lateran und Clemens' VI. Neubau St. Peter substituiert, so hieß ein unter Urban V. erbauter Trakt schließlich sogar direkt $>$ Roma . Siehe zur Architektur des Avignoner Papstpalastes und den mit dieser verbundenen symbolischen Implikationen Bernhard Schimmelpfennig, »Die Funktion des Papstpalastes und der kurialen Gesellschaft im päpstlichen Zeremoniell vor oder während des großen Schismas«, in: Genèse et débuts du grand schisme d'Occident, Paris 1980 (Colloques internationaux du Centre national de la recherche scientifique, 586), S. 317-328; ders., »Der Palast als Stadtersatz. Funktionale und zeremonielle Bedeutung der Papstpaläste in Avignon und im Vatikan«, in: Zeremoniell und Raum (12001600), Sigmaringen 1997 (Residenzforschung, 6), S. 239-256; sowie Gottfried Kerscher, Architektur als Repräsentation. Spätmittelalterliche Palastbankunst zwischen Pracht und zeremoniellen Voraussetzungen. Avignon - Mallorca - Kirchenstaat, Tübingen und Berlin 2000. 

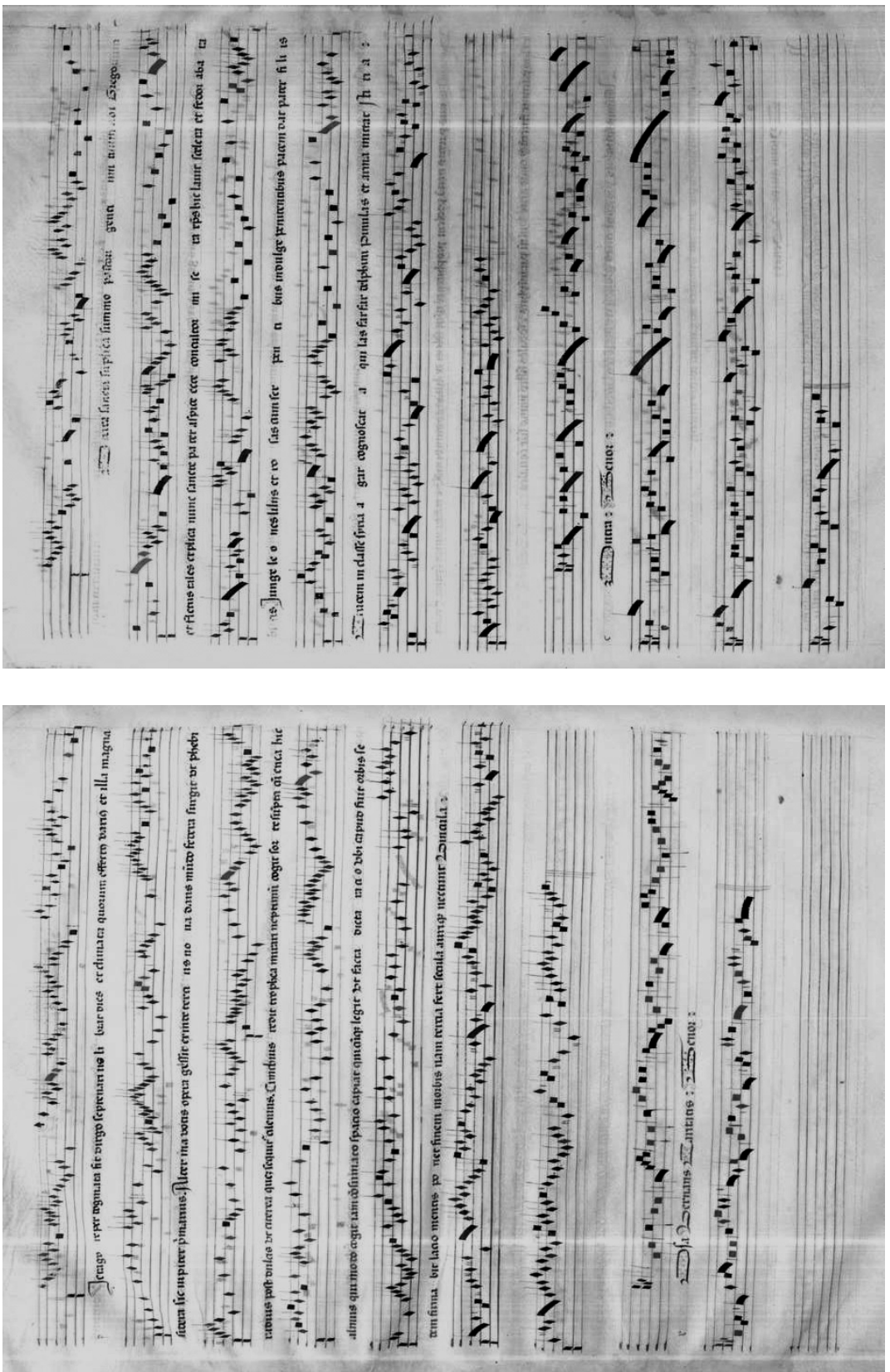

Abbildung 3a: Anonymus, Motette Pictagore per dogmata | O terra sancta | Rosa vernans (Codex Chantilly, fol. $63^{\mathrm{v}}-64^{\mathrm{r}}$ ) 
bußen erlitten, da die seit 1368 in China regierende Ming-Dynastie die dortige lateinische Mission beendete und das Christentum durch Kriegszüge des Mongolenführers Timur Lenk zugleich auch in Mittelasien vor dem Niedergang stand. Dass man, obwohl man den Apostolischen Stuhl argumentativ nachdrücklich als überrömische Instanz zementierte und den Universalepiskopat des Pontifex propagierte, doch nach Rom in den italienischen Kirchenstaat zurückzukehren trachtete, nimmt also durchaus nicht wunder.

Exakt in diesem Zusammenhang zentralistisch-monarchischen Universalismus $^{53}$ ist nun auch Pictagore per dogmata $\mathrm{zu}$ verorten, insofern die zugrunde liegenden Texte einerseits im Motetus ganz explizit und unmissverständlich einen prononcierten Appell zur Eroberung des Heiligen Landes beinhalten (1375 plante Gregor in der Tat einen Kreuzzug), andererseits im Triplum vor allem aber einen Nexus zur Rückkehr Gregors nach Rom 1376 herstellen, der eine zähe Einigung mit den Visconti von Mailand im Streit um die kirchlichen Besitztümer in Italien vorausgegangen war. Dass dieser Bezug auf die Rückverlagerung des Heiligen Stuhls an den Tiber in Rekurs auf die Aeneis mit der Landung des Helden in Latium hergestellt wird, folgt dabei über die so schlagende historisch-mythologische Parallele hinaus ${ }^{54}$ offensichtlich dem Usus, den Papst in die Tradition des römischen Kaisertums zu stellen und ihm als >princeps< im Sinne der >translatio imperii< folglich Weltherrschaftsansprüche über das christliche Imperium, den >orbis christianus $<$, zuzubilligen.

Wenn im Zuge dessen aber zugleich in extenso ausgerechnet ein allegorischer Verweis auf das Planetensystem in seiner siebengliedrigen Ordnung mit Jupiter, Mars, Sonne (Phöbus), Venus (Cytherea), Merkur (Cyllenius), Mond (Cynthia) und dem in Vers 16-24 evozierten (eben gezielt nicht genannten, weil fehlenden, Gregor XI. meinenden) Saturn bemüht wird, ist gerade auch dies überaus signifikant - zumal die Allegorie unter den Vorzeichen der prominent hervorgehobenen Namensnennung von Pythagoras als dem Entdecker und Lehrmeister des Zahlenprinzips des sseptenarius< (»Pictagore per dogmata fit virgo septenarius«), dem Erforscher der planeta-

53 Vgl. insgesamt auch Götz-Rüdiger Tewes, »Das spätmittelalterliche Papsttum und die Problematik der Raumerfassung «, in: Raum und Raumvorstellungen im Mittelalter (wie Anm. 23), S. 603-612; sowie Hans-Joachim Schmidt, Kirche - Staat - Nation. Raumgliederung der Kirche im mittelalterlichen Europa, Weimar 1999 (Forschungen zur mittelalterlichen Geschichte, 37).

54 Spätestens mit der Erfolgsgeschichte des Ovide moralisé (1291-1328) dürfte dieser Konnex zum Allgemeingut geworden sein, denn schon hier wird Äneas mit der »Sainte Yglise« verglichen. 
rischen Ordnung und dem >Urvater $<$ der Musiktheorie entfaltet wird. Denn hier ist unmittelbar eine nicht nur gleichsam vorzeitliche Dimension aufgespannt, sondern vor allem auch jene kosmisch-räumliche Komponente angesprochen, die - und dies ist das Entscheidende - über die Figur des Pythagoras zugleich in sinnfälliger Weise die Analogie von >musica coelestis<| >musica mundana< und >musica instrumentalis< aufruft. Und dass diese hier implizierte Mittlerfunktion der Musik wiederum in direktem Konnex zum Pontifex zu deuten ist, dürfte insofern einsichtig sein, als Gregor XI. vermittels des Tenors »Rosa vernans caritatis« (siehe Abbildung 3b) abgesehen vom Bezug zum Wappen Pierre Rogers de Beaufort und seinem Geburtsort Rosiers-d’Égletons - ebenso als Bindeglied zwischen Gott und Welt akklamiert wird, symbolisiert die Rose doch Christus als »mediator Dei et hominum« und benennt damit eine Position, die dem Papst als >vicarius Christi< als dessen oberstem Sachwalter und Nachfolger zugeeignet wird. $>$ Musica< und Pontifex werden so in gewisser Weise auf gleicher, zumindest vergleichbarer Stufe zum Medium bzw. Scharnier zwischen Schöpfergott und göttlichem Heilsplan sowie dessen irdischem (und menschlichem) Abglanz, wobei über die Parallelstellung zu Pythagoras zugleich eine (gleichermaßen intellektuelle wie machtpolitische) quasi-überzeitliche >translatio<Sukzession und Kontinuität zur Antike suggeriert wird.

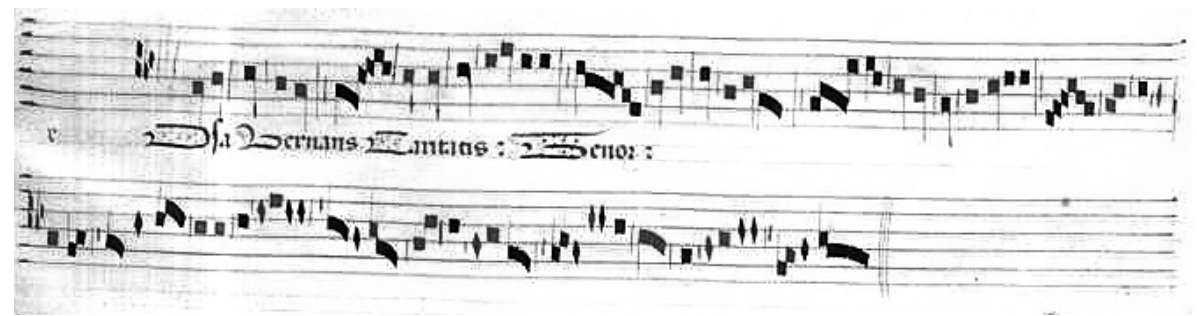

Abbildung 3b: Anonymus, Motette Pictagore per dogmata | O terra sancta | Rosa vernans, Tenor (Codex Chantilly, fol. 63v , Ausschnitt)

Wie sinnstiftend mit diesem schillernden Bedeutungs- und Assoziationsspektrum ihrerseits auch die musikalische Struktur der Motette interagiert und zwar gleichermaßen >intellectus<, >auditus< und >visus< ansprechend -, sei durch punktuelle Hinweise auf ganz verschiedene Aspekte umrissen. Dass nämlich erneut vor allem die Denk- und Deutungsmatrix der >musica mensurabilis< und die durch die isorhythmische Konzeption des Stückes minutiös durchrationalisierte Zeitgestaltung eine eminente Rolle spielen, dürfte einsichtig sein. Und so mag es diesbezüglich zunächst genügen hervorzuhe- 
ben, dass sich die Einzelverse der Oberstimmen über einem Tenor-Fundament aus abwechselnd jeweils sieben bzw. sechs Tönen gruppieren, so dass also in bekannter Weise die >numerositas< von Universalität und Vollkommenheit ins Werk gesetzt scheint.

Zum anderen ist insbesondere auch auf die mit der komplexen mensuralen Faktur unmittelbar korrelierende Ebene der graphischen Fixierung der Motette aufmerksam zu machen, also auf die gerade im Codex Chantilly so zentrale Kategorie der Verschriftlichung und Visualisierung von Musik ${ }^{55}$ (die hier zusätzlich zudem auch durch die klanglichen Allusionen der außergewöhnlich latinisierten Nomenklatur »Pictagore zum Piktographischen besonders indiziert sein mag): Denn der stete Wechsel zwischen imperfectio und perfectio, der als spezifischer Eingriff in die temporale Struktur zu den vorrangigen Gestaltungsprinzipien des Stückes zählt und für sich genommen bereits auf die volle Verfügungsgewalt über (musik-)zeitliche Operationen und Organisationsmechanismen weist, wird durch die wirkmächtige Kolorierung namentlich im Tenor gerade auch optisch unmittelbar augenfällig gemacht.

Im Leseakt, der die Zeitlinearität der temporalen Performanz nicht nur retardiert und entautomatisiert, sondern zugleich in Richtung einer an der zweidimensionalen Raumfläche des Folianten orientierten Simultaneität transzendiert, ${ }^{56}$ scheint dadurch die Qualität der elaborierten chronologischen Verlaufskonfigurationen multisensorisch durch einen visuellen Reiz

55 Dass die berühmten herz- bzw. kreisförmig notierten Chansons Baude Cordiers dem Codex nachträglich vorangestellt wurden, bestätigt die Diagnose gleichsam post festum aus der Perspektive des einstigen Eigentümers bzw. Kurators der Sammlung und mag so insgesamt die Sensibilität gegenüber notationstechnischen Fragen des Codex schärfen. Man denke aber auch an die wohl durchgängig geplanten Illuminationen, wie sie letztlich allerdings nur auf fol. $37^{\mathrm{r}}$ ausgeführt wurden (hier freilich frappierend ähnlich wie in der Richental-Chronik auditus< und visus< thematisierend). Siehe insgesamt die Beiträge im Kapitel »Reading the Notation« in: A Late Medieval Songbook and Its Context (wie Anm. 3), S. 133-227. Zum größeren Kontext siehe auch: Wolfgang Fuhrmann, Notation als Denkform. Zu einer Mediengeschichte der musikalischen Schrift, in: Musiken. Festschrift Christian Kaden, hrsg. von Katrin Bicher, Jin-Ah Kim und Jutta Toelle, Berlin 2011, S. 114-135.

$56 \mathrm{Vgl}$. zu diesem Komplex, der eng an die wachsende Literarisierung des Mittelalters sowie an das Erstarken des privaten Lesens gekoppelt scheint: Ivan Illich, »Ein Plädoyer für die Erforschung der Laienliteralität«, in: Von Aufbruch und Utopie. Perspektiven einer neuen Gesellschaftsgeschichte des Mittelalters, hrsg. von Bea Lundt und Helma Heimöller, Köln 1992, S. 181-201; Horst Wenzel, Hören und Sehen, Schrift und Bild. Kultur und Gedächtnis im Mittelalter, München 1995; Paul Saenger, Space Between Words. The Origins of Silent Reading, Stanford 1997; sowie Deborah MacGrady, Controlling Readers. Guillaume de Machaut and His Late Medieval Audience, Toronto 2006. 
substituiert. Die hermeneutische Aktivität, die durch das im Akt des Lesens vollzogene Navigieren und Kombinieren der Einzelstimmen freigesetzt wird, erhält mit der wirkmächtigen Rubrizierung gezielte Impulse, die auf die semantischen Implikationen von temporaler Komplexität und Souveränität deuten, zumal der sinnergründende Lesevorgang eines >silent reading per se auf Mechanismen der Zeitaufhebung bzw. -überwindung durch Kontemplation und Versenkung zu zielen scheint, um so aus theologischer Perspektive in gewissem Maße Teilhabe an der göttlichen Zeit zu erwirken. (Dass hierbei optisch zugleich das Rot der textlich evozierten Rose als Sinnträger des »mediator Dei et hominum« realisiert wird, mag gerade auch in diesem zeittranszendentalen Sinne kaum Zufall sein.)

Vor der Perspektive eines ganz essentiell zur Bedeutungsschicht der Ars subtilior hinzuzudenkenden $>$ Mehrwerts $<$ der graphischen Notierung, ${ }^{57}$ bei der vor der Folie des Nominalismusstreits in der franconischen Tradition spätestens seit Johannes de Muris der Zeichencharakter von Notation im durchaus modernen zeichentheoretischen Sinne von ssignifiant-signifié< hervorgehoben wurde, ${ }^{58}$ eröffnen sich so denn insbesondere auch für andere Aspekte der musikalischen Gestaltung tiefere Konnotationen und Sinngehalte. Im Notat äußerst auffallend exponiert, ja geradezu in dieses >eingraviert<, findet sich jedenfalls ein weiteres, durchaus auch unmittelbar auditiv erfassbares (ebenso schon bei Petre clemens zu beobachtendes) Moment, diesmal nicht der Zeit-, sondern der (Klang-)Raumkonfiguration: Der ausgreifende Ambitus der Stimmen, der in Triplum und Motetus etwa durch ein weitschweifig wellenförmiges Schriftbild optisch plastisch erfahrbar gemacht wird, erhält nämlich gerade durch die gewichtig-markanten Ligaturen

$57 »$ Many of the Ars subtilior songs were created to be seen as well as heard, and their selfreflexivity engages not only the verbal text but the musical notation, their writteness becomes part of the musical notation, so that only a reader can have access to the entire meaning of the song «. Stone, »Self-reflexive songs« (wie Anm. 3), S. 183.

$58 »$ Figura autem signum est, res musicalis est signatum $\ll-»$ Signum est ens perfectum per suam formam primariam, similiter et significatum. Unumque accidit alteri, facientes ambo unum per aggregationem quod musicalis notula nuncupatur «, definierte Johannes de Muris in seinen Notitia artis musicae; musikalische Notate seien »significativa ad placitum«. Bereits für Johannes de Grocheo ist das schriftliche Aufzeichnen von Musik ein »modus designandi vel describendi cantum «. Vgl. F. Alberto Gallo, »Figura and Regula. Notation and Theory in the Tradition of Musica mensurabilis«, in: Studien zur Tradition in der Musik. Kurt von Fischer zum 60. Geburtstag, hrsg. von Hans-Heinrich Eggebrecht und Max Lütolf, München 1973, S. 43-48; ders., "Die Notationslehre im 14. und 15. Jahrhundert«, in: Die mittelalterliche Lehre von der Mehrstimmigkeit, Darmstadt 1984 (Geschichte der Musiktheorie, 5), S. 257-356, zu Johannes de Muris insbesondere S. 272-278. 
im Contratenor eine mit Blick auf die Textaussagen überaus sinnstiftende bildhaft-symbolische Konnotation, erscheint die graphische Gestalt der Ligaturen doch eindrücklich als Discensus-Figur im Sinne des Abstiegs vom Himmel zur Erde und damit als Visualisierung des >musica mundana< >musica instrumentalis<-Prinzips sowie des >mediator<-Gedankens (siehe Abbildung 3c). Auch im Schriftbild erscheint der Papst dergestalt als Mittler einer im scholastischen Sinne raum- und zeitlosen Sphäre des göttlichen Schöpfers und einer raum- und zeitgebundenen Sphäre der irdischen Schöpfung.

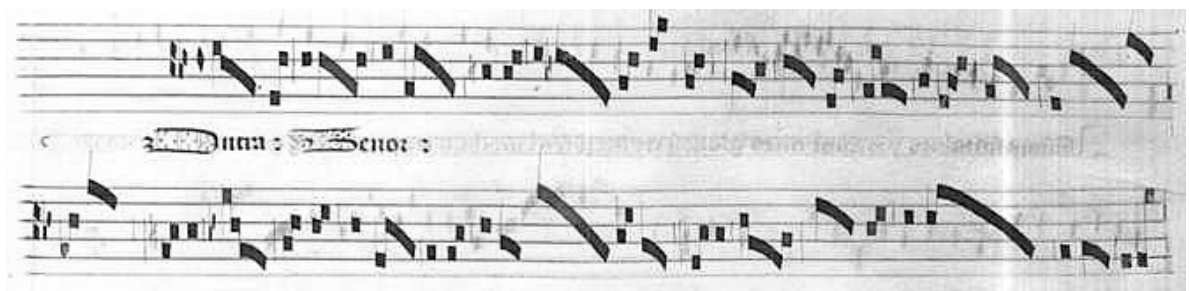

Abbildung 3c: Anonymus, Motette Pictagore per dogmata | O terra sancta | Rosa vernans, Contratenor (Codex Chantilly, fol. $64^{r}$, Ausschnitt)

\section{Schisma, Kanontechnik und kosmopolitisches Idiom}

Was sich in späteren papstbezogenen Motetten bis weit in die Zeit der Gegenpäpste hinein fortgesetzt findet, erhält durch die historische Situation des Schismas freilich noch einmal ein anderes Profil, konkretisierte sich die Frage, wer rechtmäßiger Nachfolger Petri sei, doch ganz manifest im Ringen um die jeweiligen Obödienzen, um den Rückhalt der verschiedenen snationes< und um einen primär geopolitisch-räumlich ausgetragenen Kampf um Vormachtstellung, sei es kriegerisch im Sinne der sogenannten »via facti oder eher diplomatisch über die $»$ via cessionis «. Beachtung verdienen dürften in diesem Kontext so denn insbesondere solche Kompositionen, die sich - wie etwa das anonyme Alme pater ${ }^{59}$ mit Verweis auf die Belagerung Urbans VI. durch den exkommunizierten neapolitanischen König Karl III. in Nocera - ganz konkreter historischer Ereignisse als Referenzpunkt und Deutungshorizont bedienen. 
Aber auch das Eröffnungsstück des Codex Aosta, das von einem >Guilhermus< gedichtete und einem >Nicolaus< vertonte Argi vices Poliphemus | Cum Philemon rebus pancis ${ }^{60}$ zu Ehren Johannes' XXIII. wäre diesbezüglich näher zu betrachten. Im Motetus-Text auf Schlüsselbegriffe wie »ecclesia militaris« (V. 9) und den »status orbis singularis« (V. 11) rekurrierend und die engagierte Gefolgschaft von Klerus, Chorus [!] und Armee beschwörend (V. 38-41), bietet die Komposition denn in der Tat noch einmal anders gelagerte Zugänge zur musikalischen Zeit- und Raumreflexion, wobei das gesteigerte Gespür für Kunstcharakter und Potenziale der Musik seitens der Urheber außer Frage stehen dürfte, insistieren diese doch in der zweiten Motetus-Strophe (die nach dem Exordium den Beginn der eigentlichen Motette markiert) in autopoetischer Weise expressis verbis auf die »armonie musicali «, das »scema rethoricum «, die »tinnitus liberali« und das »melos«, ehe sie sich in den drei Schlussversen des Envoi im Sinne einer abschließenden Signatur schließlich selbst beim Namen nennen. ${ }^{61}$ Vor der Folie eines solchermaßen insgesamt erhöhten Kunst- und Autorbewusstseins gewinnt es denn fraglos ganz besondere Relevanz, dass im außergewöhnlich langen (bezeichnenderweise $3 \times 7$ Mensuren umfassenden) zweistimmigen Eingangskanon mittels der so sinnfälligen topischen Qualität, die diese Satzfaktur um 1400 erlangt hatte, ${ }^{62}$ überaus kunstfertig und markant Zeitlichkeit bzw. Zeitlosigkeit und Ewigkeit thematisiert werden, während die vier folgenden Taleae durch die Kombination von italianisierender Duettstruktur in den Oberstimmen plus gleichsam nördlich-schlichten, nüchtern-strikt entworfenen isorhythmischen Tenor-Perioden gewissermaßen einen Universalität formulierenden international-polyglotten Stil zu erproben scheinen, ${ }^{63}$ also quasi-kosmopolitisch den päpstlichen Geltungsanspruch für den gesamten >orbis christianus< artikulieren.

60 Überliefert in: Codex Aosta 15, fol. 4v-7; Edition: PMFC XIII, S. 220-227. Die dortige Zuschreibung an einen Nicolaus Frangens de Leodio scheint ebenso zweifelhaft wie diejenige an Nicolaus Zacharias. Die plausibelsten Argumente sprechen derzeit wohl für Nicolas Grenon (vgl. Marian Willner Cobin, The Aosta Manuscript. A Central Source of Early-Fifteenth-Century Sacred Polyphony, PhD Diss. Univ. of New York 1978, S. 257-279).

61 Vgl. zum Kontext etwa Lütteken, »Autobiographische< Musik? (wie Anm. 3); sowie Andrea Lindmayr-Brandl, »Die Autorität der Namen - Fremd- und Eigensignaturen in musikalischen Werken der Renaissance «, in: Autorität und Autoritäten in musikalischer Theorie, Komposition und Auffübrung, hrsg. von Laurenz Lütteken und Nicole Schwindt, Kassel u.a. 2003 (Trossinger Jahrbuch für Renaissancemusik, 3), S. 21-40.

62 Vgl. etwa Gilles Dulong, »Canons, palindromes musicaux et textes poétiques dans les chansons de l'Ars nova«, in: Canons and canonic techniques (wie Anm. 23), S. 61-82.

63 Vgl. zu einem solchen Kontext im weiteren Sinne auch Giuliano di Bacco und John Nádas, 


\section{Päpstliche Legitimation, Handlungsanweisung und regelgebender Paratext}

Dass ab den 1380er Jahren daneben insbesondere diejenigen Kompositionen, die wie Gilet Veluts Benedicta viscera | Ave mater | Ora pro nobis ${ }^{64}$ oder Johannes Carmens Venite adoremus | Salve sancta ${ }^{65}$ (siehe Abbildung 4) eben keine Papstpanegyrik im engeren Sinne betreiben, sondern im Allgemeinen die Bitte um das Ende des Schismas formulieren, der Gattung Motette zugehören, scheint signifikant, zumal sich beide genannten Stücke einer Strategie bedienen, die darin besteht, den zugrunde liegenden mensuralen und proportionalen Plan des Tenors in einen wortsprachlichen Kanon auszulagern. ${ }^{66}$ Dies aber birgt mindestens zwei Implikationen: Denn zum einen wird hier explizit die gleichsam architektonische Elaboriertheit und Raffinesse noch einmal eigens herausgestellt und somit ein exklusiv-elitärer Status von Musik als einem sarcanum< betont, bei dem sich Faktur und Bauprinzip nur demjenigen erschließen, der in einem intellektuellen, Expertise verlangenden Akt die lateinischsprachige Handlungsanweisung auf die Noten appliziert, also Wort- und Notentext in einer Art >cross reading< kombiniert und so wiederum über die Momente von Retardement, Entautomatisierung und Versenkung Quasi-Zeitlosigkeit erwirkt. (Zwar pragmatisch, aber in diesem Sinne letztlich kontraproduktiv wurden in einigen Handschriften zur praktischen Ausführung zugleich ausnotierte sogenannte ssoli tenores< bzw. stenores ad longum $<$ implementiert. ${ }^{67}$ )

Verso uno stile internazionale della musica nelle capelle papali durante il Grande Scisma (13781417). Il caso di Johannes Ciconia da Liège, Vatikanstadt 1994 (Capellae Apostolicae Sixtinaeque Collectanea Acta Monumenta, III).

64 Überliefert in: Codex Oxford 213, fol. 102 $-103^{\mathrm{r}}$; Edition: CMM 112, S. 137-145.

65 Überliefert in: Codex Oxford 213, fol. 138 $-139^{\mathrm{r}}$; sowie Codex Bologna Q 15, fol. 224 $4^{\mathrm{v}}-225^{\mathrm{r}}$; Edition: CMM 11, S. 39-48. In Codex Oxford 213, fol. 139 ${ }^{\mathrm{v}}-140^{\mathrm{r}}$, schließt sich im Übrigen unmittelbar eine weitere Motette mit Schisma-Bezug an: Johannes Tapissiers vierstimmige Marienmotette Eya dulcis | Vale placens (Edition: CMM 11, S. 72-78).

66 Im Einzelnen lauten die Anweisungen wie folgt. Bei Velut: »Canon: qui primum dicitur de modo perfecto, temporis imperfecti perfecte, $2^{\circ}$ de modo imperfecto perfecti perfecte, $3^{\circ}$ de modo perfecto et de tempore imperfecto imperfecte.« - Contratenor dicitur ad modum tenoris«. Bei Carmen: »Tibi color cantus bis pronunciandus unde duo colores de maiori in tempore imperfecto ultimus cum primo de minori in tempore perfecto item secundus et ultimus de eadem in tempore imperfecto. Vgl. insgesamt: Charles Turner, »Sub obsurite quadam ostendens. Latin Canon in the Early Renaissance Motet«, in: Early Music 30 (2002), S. 165-187.

67 J. Michael Allsen, »Tenores ad longum and rhythmic cues in the early fifteenth-century motet «, in: Plainsong and Medieval Music 12 (2003), S. 43-69. Siehe auch Keith Mixter, »Tenores ad longum in the MS Bologna Q 15«, in: Bericht über den Internationalen Musikwissenschaftlichen 
Zum anderen wird die Fundamentalstimme des Tenors, auf der die zeitliche und klangräumliche Struktur der gesamten Motette basiert, durch eine dem musikalischen Text im engeren Sinne externe, regelgebende Instanz determiniert, also von Außen durch einen Paratext gesteuert. Inwiefern dies wiederum naheliegenderweise als Verweis auf den >deus artifex<, den göttlichen Regelstifter bzw. seinen göttlichen Heilsplan auszulegen wäre, der eben explizit außer- respektive überhalb der Musik selbst figuriert (bzw. mit Blick auf die Mise-en-page von Venite adoremus in Bologna $Q 15^{68}$ die Basis der Musik bietet), und wie dies schließlich auf einen einzigen regelkonform allein durch Gott gesandten Papst als legitimem obersten Repräsentanten Gottes und Harmoniestifter auf Erden weiterzudenken ist, bliebe im Einzelnen zu erörtern. Doch drängt sich der Gedanke auf, dass analog zur musikalischen >Unordnungく, wie sie aus einer falschen oder Nicht-Anwendung des Kanons resultieren würde, auch das nicht-gottkonforme Schisma als Quelle weltlicher >disharmonia< zu interpretieren ist. Oder anders herum formuliert: So wie die Devise den einen, einzig sinnvollen rhythmischen Plan der Motette definiert, so kennt die göttliche Weisung nur einen einzigen wahren Träger des Papstamtes.

Als zusätzlich entscheidende Deutungsmatrix dürfte hier jedenfalls ebenso die platonische Verbindung von >consonantia< und >concordia< $\mathrm{zu}$ sehen sein wie die augustinische Analogie zwischen Chorgesang und kirchlicher Einheit. Und dass sich letztlich auch in der Auflösung des Quasi-Rätselcharakters, bei dem sich ein höherer Sinn nur durch das strikte Transferieren und Anwenden des Kanons auf den Tenor erschließt, vielfach tiefere Sinnebenen eröffnen, steht ebenso außer Frage: So resultiert aus der Devise in Venite adoremus beispielsweise eine Diminutionsanlage in der Proportion 9:7, was - in einem Akt der Exegese gesprochen - auf das Verhältnis potenzierter Trinität (also des göttlichen Regelgebers bzw. seines nur durch diesen >regulär< bestimmbaren weltlichen Sprachrohrs) zu der von ihr beanspruchten himmlisch-irdischen Universalität verweisen dürfte.

Kongress, Berlin 1974, hrsg. von Hellmut Kühn und Peter Nitschke, Kassel 1980, S. 236f.; ders., "Solus Tenor«, in: Handwörterbuch der musikalischen Terminologie, hrsg. von Albrecht Riethmüller, 16. Auslieferung, Stuttgart 1988/1989; sowie Shelly Davis, »The Solus Tenor in the fourteenth and fifteenth centuries«, in: Acta musicologica 39 (1967), S. 44-64, und 40 (1968), S. 176-178.

68 Vgl. zum Kontext auch Margaret Bent, »A Contemporary Perception of Early Fifteenth-Century Style. Bologna Q 15 as a Document of Scibal Initiative«, in: Musica Disciplina 41 (1987), S. 181-201; sowie dies., »Manuscripts as Répertoires. Scribal Performance and the Performing Scribe «, in: Atti del XIV Congresso della Società Internazionale di Musicologia 1987, hrsg. von Angelo Pompilio u.a., Turin 1990, S. 139-152. 

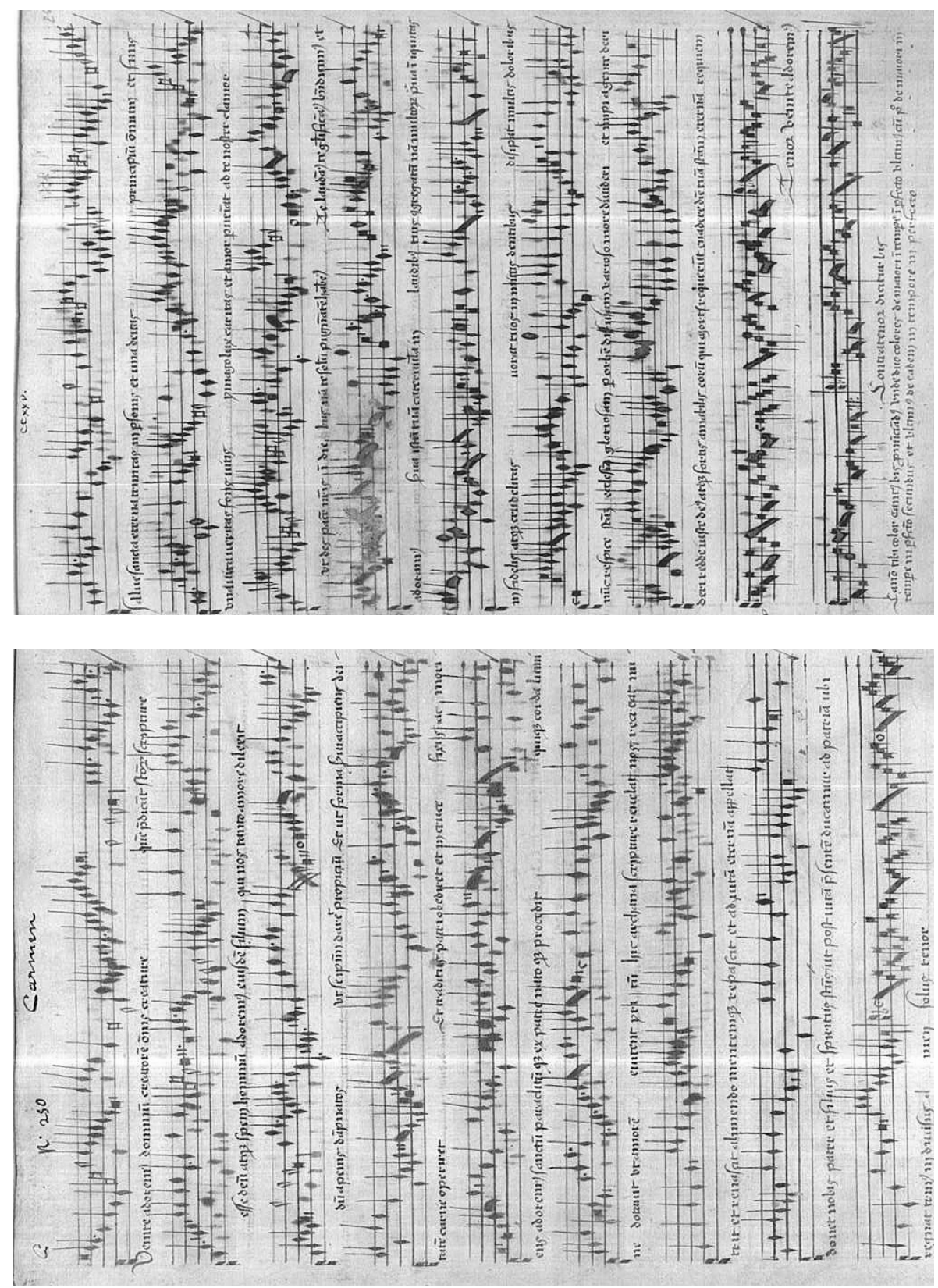

Abbildung 4: Johannes Carmen, Motette Venite adoremus | Salve sancta (Codex Bologna Q 15, fol. $224^{\mathrm{v}}-225^{r}$ ) 


\section{Verhöflichung, Ars subtilior, Ikonozität und Mise-en-page}

Nicht minder signifikant als das Phänomen wortsprachlicher Kanones in den Schisma-Motetten erscheint zugleich die Tatsache, dass sich zu dieser Zeit die gattungsmäßigen Schwerpunkte der ganz konkret papstbezogenen und -huldigenden Komposition zu verlagern scheinen. In der Tat rückten in den beiden Dekaden um 1400 nicht länger Motetten, sondern liedhafte Formen in den Fokus, und damit jene Genres, die zu dieser Zeit bekanntlich nicht nur insgesamt zu florieren begannen, sondern vor allem im südfranzösischen Raum immer deutlicher auch eine Steigerung der Subtilitäten und Artifizialitäten verfolgten. Lässt sich dies im Grunde sowohl für den Bereich von Melismatik, elaboriertem Satz und formaler Konstruktion diagnostizieren, so scheinen hierbei - unter deutlicher Erweiterung der Zeitdimensionen der >grandes ballades - insbesondere die rhythmischen Varianzen und Ausdifferenzierungen der Tonorganisation espritvoll ausgereizt. ${ }^{69}$

Just in diesem Kontext nun ist es fraglos aufschlussreich, dass - abgesehen von der anonymen Motette Gaudet et exultet, die Urban VI. zugunsten von Clemens VII. ausspielt ${ }^{70}$ - das Gewicht unter Clemens' Pontifikat nunmehr tatsächlich eindeutig auf die >formes fixes< fällt, namentlich auf lateinisch- und vernakularsprachliche Balladen. Denn abgesehen von dem naheliegenden Befund, dass sich das Papsttum mit dem Liedrepertoire im Sinne einer >Verhöflichung deutlicher in einem dezidiert feudal-weltlichen Kontext verortete und sich zudem mittels Volkssprachlichkeit und Wahl populärer Formen von der distinguiert-exklusiven $>$ maiestas $<$ Repräsentation hochkomplexer Motetten stärker hin zu einem sich öffnenden Partizipationsdenken im Sinne übergreifender kirchlicher Heilsgemeinschaft verlagerte, ermöglichte der Gattungswechsel zudem, noch einmal auf andere Art und Weise den päpstlichen Zeit- und Raumanspruch zu explizieren, und zwar in einem Medium, das - nota bene: nur vordergründig - aufgrund geringerer Stimmenzahl, Eintextigkeit und einer im Vergleich zu einer isorhythmischen Anlage einfacher mitvollziehbaren Formstruktur eine größere Unmittelbarkeit aufzuweisen scheint, möglicherweise also den hörenden Nachvollzug stärker gewichtet. (Wie zu zeigen sein wird, spielen freilich gleichwohl auch andere, >intellektualistische< Faktoren entscheidend in die Sinnstrukturen dieses Repertoires hinein.)

69 Vgl. etwa den Überblick bei Nicole Schwindt, »Die Zeit der Formes fixes: Die Chanson als europäisches Modell im 14. und 15. Jahrhundert«, in: Musikalische Lyrik, hrsg. von Hermann Danuser, Laaber 2004 (Handbuch der musikalischen Gattungen, 8), Teil I, S. 138-175.

70 Überliefert in: Basel, Universitätsbibliothek, Musikfragmente I-II. 
Neben Conradus de Pistoias Veri almi pastoris, ${ }^{71}$ Bartolomeus de Bononias Arte psallentes ${ }^{72}$ und Magister Egidius' Courtois et sage ${ }^{73}$ bieten für dieses Repertoiresegment wohl insbesondere Mayhuet de Joans Inclite flos orti Gebennensis $^{74}$ (siehe Abbildung 5) und Philippus de Casertas Par les bons gedeons $^{75}$ ebenso originelle wie paradigmatische Beispiele, nicht zuletzt da beide im Repertoire der Zeit offenbar insofern eine Zentralstellung einnahmen, als sie zusammen in Doppelüberlieferung sowohl in Modena als auch in Chantilly erhalten sind. (Par les bons gedeons findet sich zusätzlich gar noch in Turin, wo der Text allerdings - ebenso bezeichnend wie prekär aufgrund der anders gelagerten Obödienz durch einfachen Austausch von Wörtern spitzfindig umgedeutet und der »souverayn pape« Clemens so zum »antipape« umgewertet wurde.)

Dabei eröffnet bereits Inclite flos ${ }^{76}$ auf textlicher Ebene durch Verweise auf die Genfer Herkunft sowie auf die spanische und französische Obödienz des Papstes, aber auch durch Schlüsselbegrifflichkeiten wie etwa »orbem« erneut geographisch-geopolitisch-räumliche Dimensionen. Musikalisch manifestieren sich diese dabei einmal mehr vor allem durch demonstrative Gegenbewegungen und den (im Wortsinne) raumgreifenden Ambitus der einzelnen Stimmen: Vollkommenheit und Ganzheit evozierende Oktav in Diskant und Tenor, diese im Contratenor überschreitend zur None als Trinitätsverweis. Insofern die auffallenden Auf- und Abwärtsbewegungen sowie Stimmkreuzungen der Unterstimmen zugleich auf Kreuzestod bzw. Discensus und Ascensus Christi verweisen mögen, ergibt sich zudem auch wiederum im Sinne von Begegnung, Versöhnung und Vermittlung zwischen Himmel und Erde eine in Hinblick auf Legitimation und Funktionsgewalt des Stellvertreters Christi fruchtbare Deutungsebene.

71 Überliefert in: Modena 5.24, fol. 36"v Edition: CMM 53/III, S. 221-223.

72 Überliefert in: Modena 5.24, fol. 37'-38 ${ }^{\mathrm{r}}$; Edition: CMM 53/III, S. 190-193.

73 Mit dem personalisierenden Achrostichon CLEMENS. Überliefert in: Modena 5.24, fol. $35^{\mathrm{r}}$, und Paris 6771, fol. 54 ${ }^{\mathrm{r}}$; Edition: $C M M$ 53/I, S. 41-43.

74 Überliefert in: Modena 5.24, fol. $15^{\mathrm{r}}$, und Codex Chantilly, fol. 41 $\mathrm{l}^{\mathrm{r}}$; Edition: CMM 53/III, S. $200 f$.

75 Überliefert in: Modena 5.24, fol. 31 ${ }^{\mathrm{r}}$, Codex Chantilly, fol. 45 $5^{\mathrm{v}}$, und Turin 2, fol. $5^{\mathrm{v}}$; Editionen: CMM 53/I, S. 154-157, und PMFC XIX, S. 70-73.

76 Vgl. zu diesem Stück auch Yolanda Plumley, »Citation and Allusion in the Late Ars Nova«, in: Early Music History 18 (1999), S. 287-363; sowie dies., »An xpisode in the south«? Ars subtilior and the Patronage of French Princes«, in: Early Music History 22 (2003), S. 103-168. 


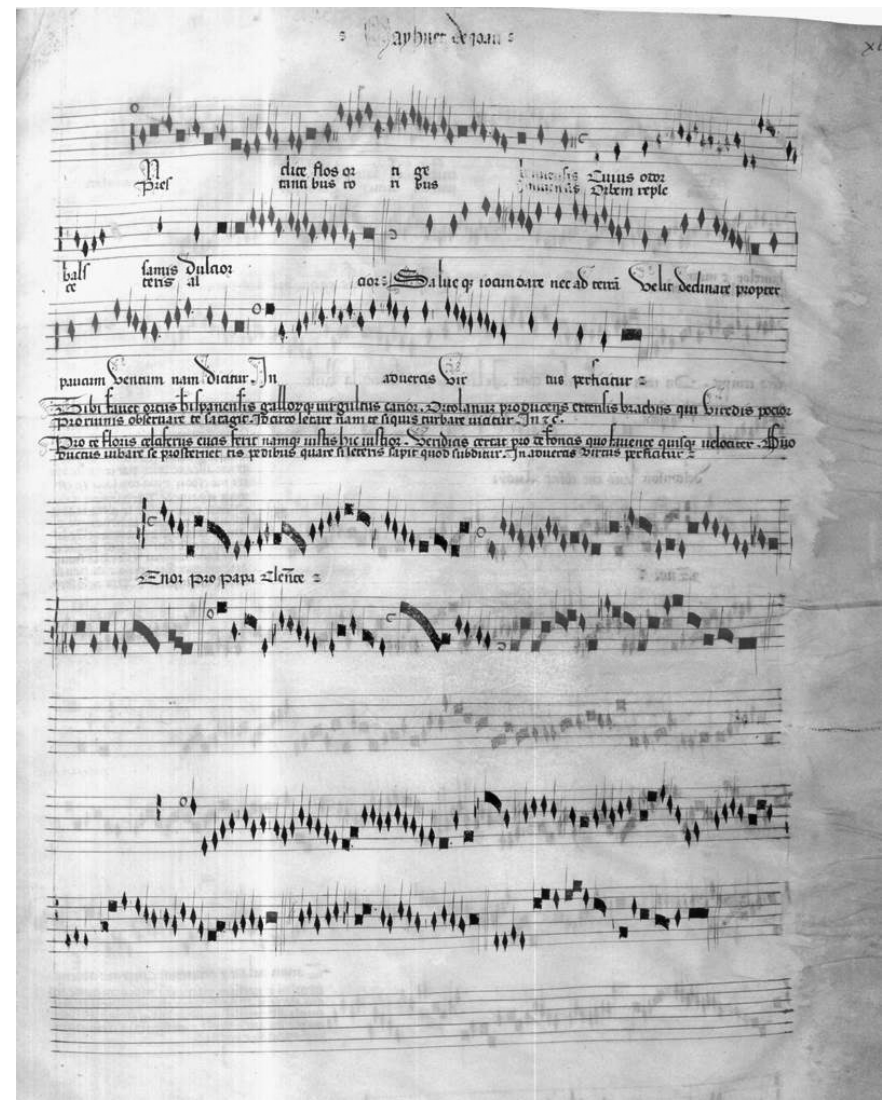

Abbildung 5:

Mayhuet de Joan, Ballade Inclite flos orti Gebennensis (Codex Chantilly, fol. $41^{r}$ )

Komplementiert wird die räumliche Komponente dabei durch temporale Aspekte wie die Tatsache, dass im >Tenor pro papa Clemente $<$ im Zusammenspiel von >significationes numerorum $<$ und Zurschaustellung rhythmischer Flexibilität und Varianz - auf je drei Mensuren je sieben Töne in je ganz unterschiedlicher rhythmischer Kombination verteilt sind. (Auch die Huldigung an den siebten Papst namens Clemens spielt hierbei freilich wieder eine entscheidende Rolle.) Vor allem aber scheint zugleich insgesamt der sozusagen planvolle Einsatz aller vier Mensurmöglichkeiten ergründet und dargelegt, die Kombinationspalette aus tempus und prolatio voll ausschöpfend und dabei kunstvolle Simultankombinationen verschiedener Mensuren generierend.

Gerade dieses demonstrative Ausloten des temporalen Gefüges wird nun im Codex Chantilly bezeichnenderweise insbesondere wieder auf einer visu- 
ellen Ebene drastisch erfahrbar und im doppelten Wortsinne sschau<-bar gemacht: So erscheinen zwar die üblichen Tempus-Zeichen, doch werden die prolationes maior und minor nicht wie sonst in diesem Codex Usus durch Punkte signalisiert, sondern durch ein geradezu exzentrisch zu nennendes Alternieren zwischen schwarzer und roter Notation. ${ }^{77}$ Diese augenfällige Exposition zeitlicher Komplexität mag dabei noch einmal intensiver zu der Einsicht Anlass geben, dass eben nicht nur das Hören, sondern insbesondere das Sehen und Lesen von Musik gerade auch in den lyrischen Gattungen der Ars subtilior wesentlich zum Erfassen des Bedeutungshorizonts des jeweiligen Stückes beiträgt. ${ }^{78}$ Zur auditiven Ebene sowie dem im Text der ersten Strophe evozierten olfaktorischen Reiz (»cuius odor balsamis dulcior«) tritt so bei Inclite flos in ganz besonderer Weise die Sinnenkomponente des $>$ visus<.

In der Tat dürften sich aus dieser Warte heraus weitere Fragen an die Quasi-Ikonizität der Notation anschließen. So scheint erneut - ähnlich den oben genannten Motetten - der Aspekt des Ambitus eigens graphisch hervorgekehrt, etwa in den markanten Ligaturen des Tenors sowie insbesondere in der auffallend sinusförmigen Gestalt des Contratenors, die im Sinne von >circulatio< symbolisch-allegorisch mit Blick auf Unendlichkeit und Ewigkeit auszulegen oder aber - gewissermaßen piktoral >glossierend - als subtiler Verweis auf Schicksalsrad, Hostie bzw. Weltkugel etc. zu dechiffrieren wäre -- all dies wohlgemerkt nicht ahistorisch im Verständnis einer musikalischrhetorischen Figurenlehre, sondern dezidiert in emblematischem Sinne. ${ }^{79}$ Denn zumindest scheint das Umkreisen der Mittelachse und Finalis $g$ just in der Mittelstimme (die hier im Manuskript allerdings an unterster, gleichsam >tragender< Position platziert ist) kaum zufällig. Ja, es ließe sich gar aus einer raumfokussierenden Perspektive heraus in Erwägung ziehen, inwiefern sich in dieser markanten >zentripetalen< Gestaltung nicht gar auch ein Widerhall

77 Vgl. auch Jason Stoessel, »The Interpretation of Unusual Mensuration Signs in the Notation of the Ars subtilior«, in: A Late Medieval Songbook and Its Context (wie Anm. 3), S. 179-202.

78 Vgl. auch Nicole Schwindt, »Hören - Lesen - Sehen. Raumwahrnehmung als Kontext für die Deploration Machauts«, in: Musik des Mittelalters und der Renaissance. Festschrift Klaus-Jürgen Sachs zum 80. Geburtstag, hrsg. von Rainer Kleinertz, Christoph Flamm und Wolf Frobenius, Hildesheim 2010 (Veröffentlichungen des Staatlichen Instituts für Musikforschung Preußischer Kulturbesitz, 18 / Studien zur Geschichte der Musiktheorie, 8), S. 253-281.

79 Vgl. diesbezüglich etwa Eisenberg, The mirror of the text (wie Anm. 23); sowie übergreifend: Manfred Lurker, Der Kreis als Symbol im Denken, Glauben und künstlerischen Gestalten der Menschbeit, Tübingen 1981; und Craig Wright, The Maze and the Warrior. Symbols in Architecture, Theology, and Music, Cambridge 2001. 
einer Art quasi-heliozentrischen Weltbildes eingefangen finden könnte (Achsenton $\mathfrak{g}=$ sol $=$ Sonne), wie es just in dieser Zeit gerade im Umkreis des französischen Hofes (und damit in direkter Nähe zu Clemens VII.) auf aristoteleskritische Weise durch den Bischof von Lisieux, Nikolaus von Oresme, als Denkmodell in Erwägung gezogen und diskutiert wurde (Livre $d u$ ciel et du monde, Questiones super De celo, Questiones de spera). ${ }^{80} \mathrm{Im}$ Kontext der vorliegenden Chanson wäre dies dann etwa im Sinne einer suggestiven Analogiestellung zwischen Sonne, Gott und Papst zu interpretieren.

Insgesamt jedenfalls regt gerade auch die so sorgsam-planvoll erscheinende Mise-en-page zum Nachdenken an, und es drängt sich die Frage auf, ob nicht auch dem Arrangement dreier Systeme für den Cantus und seiner durch den >Riegel< der Strophentexte markierten Demarkation zu den 2 x 2 $=4$ Systemen der Unterstimmen eine tiefere Bedeutung beizumessen wäre. Denn einerseits lässt sich die Lesefeld-Gestaltung zwar jenseits schierer Pragmatik gewissermaßen als Tribut an den Darbietungsmodus mit texttragender Oberstimme und >Begleitstimmen< werten, was mithin die Möglichkeit impliziert, den Akt der Aus- und Aufführung durch die räumliche Disposition der Codex-Seite beim Lesen gleichsam imaginationsfähig zu halten (im Sinne einer virtuellen Positionierung der Ausführenden mit quasi fluchtpunktperspektivischer Ausrichtung auf den Ziel- und Zentralpunkt des Hörers respektive Lesers). ${ }^{81}$ Zugleich indes suggeriert das Layout andererseits - im Sinne des Lesens als Dispens oder Substitut des Hörens bzw. als Auffächerung der vertikalen Klangsimultaneität in eine zweidimensionale Flächigkeit ${ }^{82}$ - einmal mehr jene schon vielfach genannte symbolträchtige >numerositas< des Göttlichen (Drei) und Kosmischen (Vier) mitsamt des damit verbundenen klerikalen und säkularen Universalitätsanspruchs der $>$ maiestas papalis $<$.

Mindestens ebenso deutlich mögen derartige graphisch-visuelle Verfahren mit Blick auf Philippus de Casertas Ballade Par les bons gedeons zutage

80 Nachdem bereits Johannes Buridanus (1295-1358) die Rotationsbewegung der Erde gelehrt hatte, erklärte Nikolaus von Oresme (1313-1382) die geozentrische und die heliozentrische Theorie für gleichermaßen plausibel, ehe dann auch Nikolaus von Kues (1401-1464) die heliozentrische Astronomie erörterte. Vgl. etwa Stefan Kirschner, »Oresme's Concepts of Place, Space, and Time in His Commentary on Aristotle's Physics«, in: Oriens - Occidens. Sciences, Mathématiques et Philosophie de l'Antiquité à l'Áge classique 3 (2000), S. 145-179.

81 Vgl. auch den Ansatz von Sylvia Huot, From Song to Book. The Poetics of Writing in Old French Lyric and Lyrical Narrative Poetry, Ithaca 1987 (S. 273: »the book is a space for performance« | »the illuminated codex becomes a stage for the execution of writing and compilation«).

$82 \mathrm{Vgl}$. diesbezüglich auch die Angaben bei Anm. 56. 
treten, die im Codex Chantilly in einer noch extravaganteren Façon überliefert ist (siehe Abbildung 6) und sich einer nachgerade outriert erscheinenden gemischten Notation mit roten und schwarzen, jeweils vollen und leeren Noten inklusive Dragmata bedient - ein hoch differenzierter Codierungsfundus, der eigens eines wortsprachlichen Kanons mit Anweisungen zur rhythmischen Auflösung des farbigen Zeichensystems bedarf: »Ista cantetur sic: note vacue nigre in proporcione dupla et rubee tam plene quam vacue in proporcione sesquialtera, et sic in tenore; alie note caudate ab utraque parte in proporcione dupla sesquiquarta; et cantantur alie sicut jacent $\ll .{ }^{83}$

Auch hier also ist dem Stück wieder eine regelgebende Instanz als Paratext beigegeben, wobei die >Handlungsanweisung< bzw. der >Regelstifter signifikanterweise sozusagen den Kern des Layouts bildet, um den herum sich die Stimmen nahezu konzentrisch gruppieren. So sehr dabei die variable metrische Struktur und rhythmische Freiheit des Cantus mit Philippus' Verdienst in Zusammenhang stehen mag, als einer der ersten in dem ihm zugeschriebenen Tractatus figurarum die Kombination differierender Mensuren theoretisiert, dabei intensiv synkopische Effekte beschrieben und ungewöhnliche Notenzeichen für die hieraus resultierenden proportionalen Relationen entwickelt zu haben, ${ }^{84}$ so sinnstiftend erscheint es im konkreten Fall, dass sich über der soliden rhythmischen Basis des Tenors, gleichsam im dauerhaften Widerstreit mit ihm permanent synkopierende Melismen und rhythmische, quasi-polymetrische Querstände ergeben. Denn hier eröffnet sich eine aussagekräftige Parallele $\mathrm{zu}$ dem im Worttext thematisierten Schisma-Streit, der es notwendig werden lasse, dass »le monde de bas en haut remis« werde. Und so wie es Clemens als dem »souverayn pape« anzuvertrauen sei, in Analogie zu den biblischen Richtern Gideon und Samson mit Stärke gegen die Ungläubigen vorzugehen, um so wieder Ordnung herzustellen, so ist es für die Musik der lateinischsprachige (bezeichnenderweise eben nicht wie der Singtext französisch formulierte) zentralplatzierte Kanon, der das planvolle Regelsystem setzt und somit Ordnung im komplexen Notenbild generiert. Papst und Musik erscheinen dabei beide in gleichem Maße

83 In Modena 5.24 lautet die Anweisung verkürzt: »Canon ballate. Note rubee cantantur in proportione sesquialtera. Note caudate ab utraque pars in sexquiquarta [recte: dupla sexquiquarta?] cantentur.«

84 Philippus de Caserta, Tractatus figurarum, übersetzt, kommentiert und hrsg. von Philip Evan Schreur als Treatise on Noteshapes, Lincoln und London 1989 (Greek and Latin Music Theory). Hierzu zuletzt: Giuliano di Bacco, »Original and Borrowed, Authorship and Authority. Remarks on the Circulation of Philipoctus de Caserta's Theoretical Legacy«, in: A Late Medieval Songbook and Its Context (wie Anm. 3), S. 329-364. 


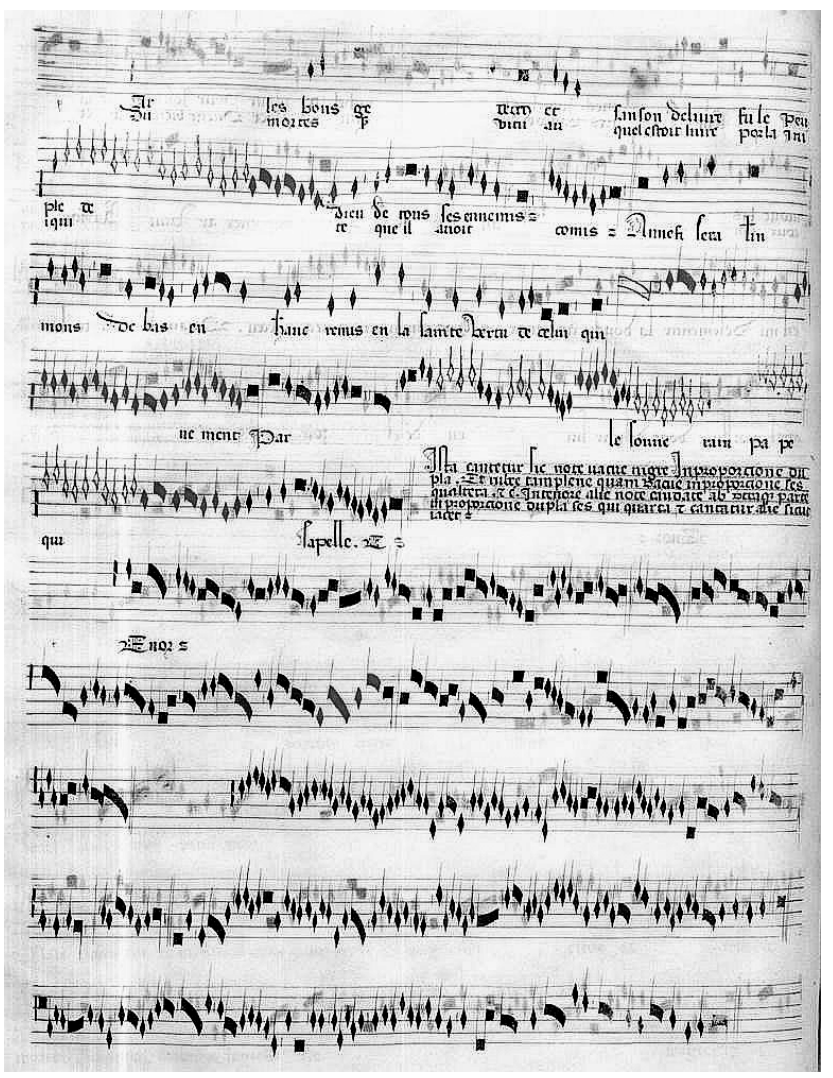

Abbildung 6:

Philippus de

Caserta, Ballade

Parles bons

gedeons (Codex

Chantilly, fol. $45^{\vee}$ )

in ganz unmittelbarer Abhängigkeit zum Schöpfergott: »Le monde est jus mis, se Diex par sum avis | Ne le remet en vie de vray sentiment.«

\section{Ewigkeitsdiskurs, ıformes fixesı und Kreisstruktur}

Weitergetrieben wird diese Sinnebene freilich durch eine zusätzliche musikalische Auffälligkeit, nämlich den formkonstituierenden Kunstgriff, das >clos<Stollenende in kompletter dreistimmiger Faktur am Refrainende zu wiederholen, womit Casertas Ballade nicht bloß Teil einer Entwicklung formaler Integrationsprozesse ist, wie sie etwa Nors Josephson für die >grande ballade< beschrieben hat. ${ }^{85}$ Vielmehr wird durch den Rekursus nämlich ein

85 Nors S. Josephson, »Intersectional Relationships in the French \Grande ballade«, in: Musica disciplina 40 (1986), S. 79-97. 
Verweissystem eröffnet, bei dem die musikalische Trägersubstanz der zentralen Textzeile »par le souverayn pape qui s'apelle Clement« zum Angelpunkt einer kreisförmig-rückläufigen Struktur gerät, was Clemens einmal mehr auch in dieser formlogischen Hinsicht als maßgebliche Ordnungsinstanz inauguriert und ihm - akzeptiert man den Symbolwert einer solchen zirkulären Formanlage in Hinblick auf Momente wie Ewigkeit und Zeitlosigkeit $^{86}$ - zudem eine gleichsam göttlich-überzeitliche, fortdauernde Gültigkeit und Souveränität attestiert.

Ließen sich solche Strategien der Verwendung auf sich selbst zurückfallender Formabläufe als Analogon zur temporalen Universalität des Papstes ein paar Dekaden später besonders plastisch auch anhand solcher Rondeaux wie Hugo de Lantins' Mirar non posso ${ }^{87}$ oder Nicolaus Zacaras Già per gran nobeltà ${ }^{88} \mathrm{zu}$ Ehren Martins V. demonstrieren, so begegnen zuvor bereits im Pisaner Umfeld der kurzen Regentschaft von Alexander V. weitere exzeptionelle Beispiele panegyrischen Komponierens in Liedform. So verleiht Antonio Zacaras zweistimmige, mit äußerster rhythmischer Varianz und Subtilitas spielende Ballata Dime, Fortuna, poi che tu parlasti ${ }^{89}$ in autobiographischem Duktus der Enttäuschung darüber Ausdruck, dass es Alexander nicht gelungen sei, sich Roms zu bemächtigen, weshalb der um 1407 von Rom nach Pisa gewechselte Zacara nicht nach Rom habe zurückkehren können, wobei die Kreisform der Ballade nicht nur mit dem Gedanken der (vereitelten) Rückkehr, sondern explizit auch mit dem Schicksalsrad Fortunas assoziiert wird..$^{90}$

Daneben gehorcht ein im Madrigalstil (aber offenbar nicht als >contrafactum $<$ ) verfasstes $O$ Petre Christus discipuli von Johannes Ciconia ${ }^{91}$ (siehe Abbildung 7) ebenso einer im Kontext des zeitgenössischen Repertoires im Grunde bemerkenswerten Schlichtheit, textlichen und stimmzahlmäßigen Selbstbeschränkung und klanglichen Abstinenz, die dabei gleichermaßen auf umso größere Eindringlichkeit und Unmittelbarkeit hin ausgerichtet sein mag, wie sie insbesondere auch den erstarkenden Konzepten päpstlicher >Solidarität<, >Egalität< und >Partizipation $<$ geschuldet scheint. Für zwei

86 Vgl. Fritz Reckow, »Rondellus / rondeau, rota«, in: Handwörterbuch der musikalischen Terminologie, nach Hans Heinrich Eggebrecht hrsg. von Albrecht Riethmüller, Stuttgart 1972; sowie abermals Eisenberg, The mirror of the text (wie Anm. 23), mit weiterer Literatur.

87 Überliefert in: Oxford 213, fol. 26r.

88 Überliefert in: Oxford 213, fol. 125할 Edition: CMM 11/VI, S. 137f.

89 Überliefert in: Turin 2, fol. $2^{\text {r }}$.

90 Im vierten Vers heißt es: »perchè surgendo la rota voltasti? «

91 Überliefert in: Bologna Q 15, fol. 259 $-260^{\text {r }}$; Edition: PMFC XXIV, S. 114-116. 

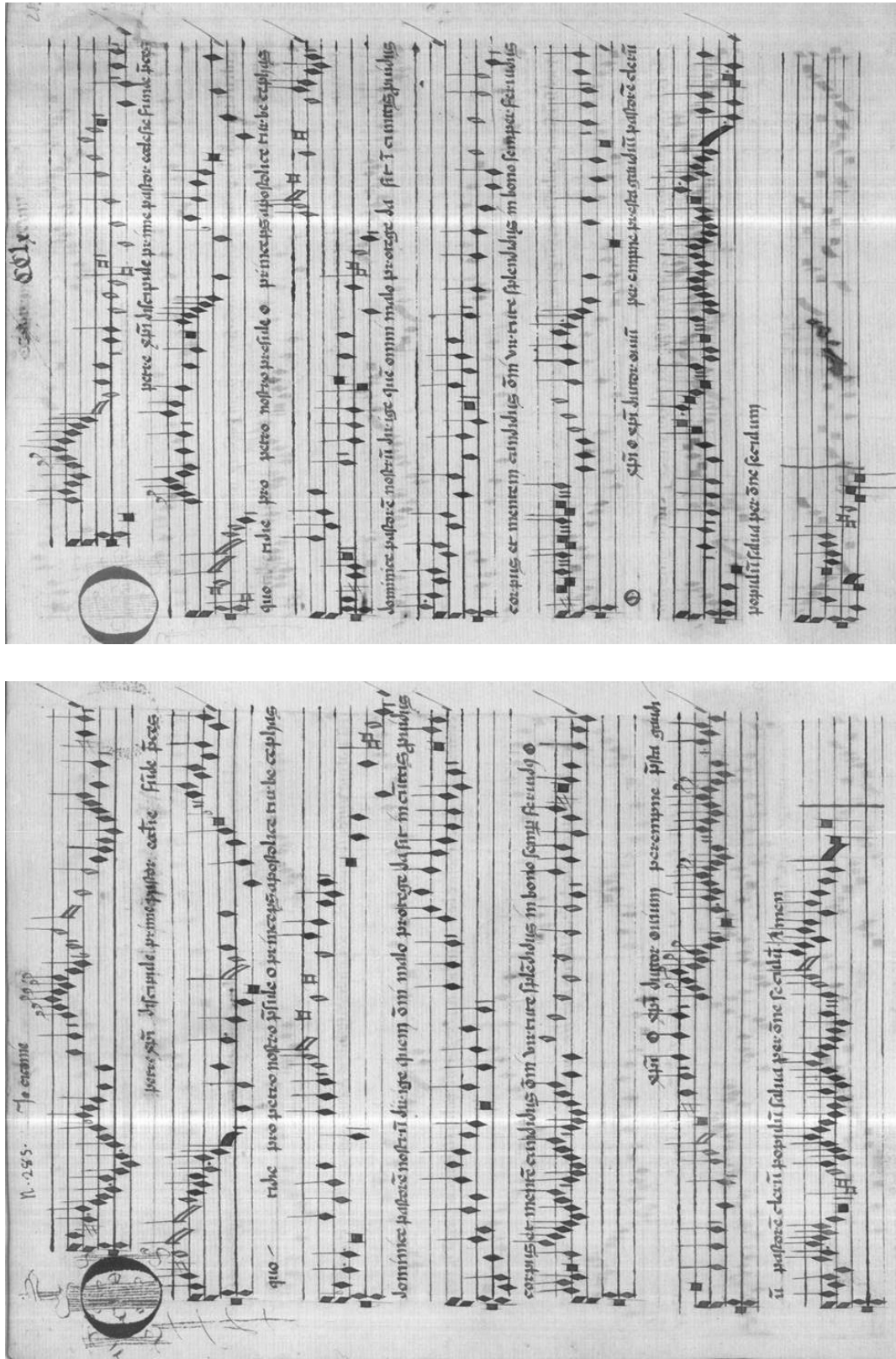

Abbildung 7: Johannes Ciconia, O Petre Christus discipuli (Bologna Q 15, fol. 259v-260') 
gleich tief geschlüsselte Tenorstimmen mit demselben Ambitus verfasst, ${ }^{92}$ fallen dabei - aufgrund der prinzipiellen Gleichheit beider Stimmen sozusagen potenziert - abermals das ostentative Auf- und Absteigen der Stimmen sowie Stimmkreuzungen und -tausche ins Auge, und zwar nicht zuletzt auch optisch-visuell dank der absoluten graphischen und layouttechnischen Parallelstellung bzw. paritätischen Gleichordnung der Stimmen in der Präsentation von Bologna $Q 15$ (inklusive korrespondierender Initialen etc.). Und auch hier werden die temporalen Implikationen solcher Ewigkeits- und Transzendenzsymbole als zentraler Subtext der Huldigung spätestens im Envoi auch wortsprachlich aufs deutlichste exponiert: $\mathrm{O}$ Christe, ductor omnium, | perenne presta gaudium; | pastorem, clerum, populum | salva per omne seculum.«

\section{Kircheneinheit, Liturgie, performative Satzfaktur und Klangraum}

Ebenfalls von Ciconia stammt das tropierte Gloria »Suscipe trinitas «, ${ }^{93}$ eines der frühesten Beispiele, bei denen man - anders als bei den bislang angeführten Stücken, die tendenziell einer päpstlichen Privatmusik zuzuschlagen wären - aufgrund des liturgischen Textes verstärkt auch von einer zeremoniellen bzw. gottesdienstlichen Verwendung einer papst- bzw. schismabezogenen Komposition ausgehen kann - was freilich auch direkte Auswirkungen auf Faktur und Klanggestalt der Musik zeitigt. Als entscheidend in Hinblick auf das zugrunde liegende musikalische Raumkonzept erscheint es dabei insbesondere, dass sich der um das Ende des Dreierschismas und eine erneute einheitliche apostolische Oberhoheit einer »unice cosmice ecclesie« bittende Tropus als zweistimmige, homophon gesetzte unus-Partie vom dreistimmigen chorus-Abschnitt des Gloria absetzt, woraus - in Verbund zudem mit der einstimmigen Intonation des Chorals - eine im Klangspektrum gezielt aufgefächerte, zudem gewissermaßen doppelchörig-räumliche Disposition entsteht; und zwar auf Basis eines Idioms, das man aufgrund der Verbindung von französischen Stilmerkmalen (wie Mensuren, Synkopierungen, Notation) und italianisierendem Duktus (rhythmisch parallel geführtes Oberstimmenpaar, Kontrast zum Tenor) - im Einzelnen

92 Vgl. zum Kontext David Fallows, »Two Equal Voices. A French Song Repertory with Music for Two More Works of Oswald von Wolkenstein«, in: Early Music History 7 (1987), S. 227241.

93 Überliefert in: Warschan 378, fol. 25 $-27^{\mathrm{r}}$; Padua D 675, fol. $2^{\mathrm{v}}$; Grottaferrata 197, fol. 9v-10v Grottaferrata s.s., fol. 2v ${ }^{\mathrm{v}}$; Edition: PMFC XXIV, S. 36-43. 
ganz anders, in der Zielsetzung aber prinzipiell ähnlich wie im Falle von Argi vices Poliphemus - mit Anne Hallmark als kosmopolitisch-polyglottes, Universalität beanspruchendes musikalisches Vokabular der Zeit bezeichnen können dürfte. ${ }^{94}$ Die unus-Partie als evidenter klanglicher Sinnträger der »unice cosmice ecclesie (in der der einstimmig-eindeutige göttliche Choral durch das legitime päpstliche Sprachrohr Gottes sozusagen kommentierendtropierend-exegetisch verdoppelt sowie der prachtvoll-vielstimmige Lobpreis gleichsam homophon kanalisiert wird) hebt sich ab von der >schismatischen< Dreistimmigkeit und dominiert dabei eine als allumfassend->weltumspannend konnotierte Musiksprache.

Auf genau dieselbe Weise (möglicherweise gar in einem Akt direkter intertextueller Bezugnahme?) wieder aufgegriffen werden sollte diese den Klangraum performativ auslotende Gestaltungsweise dann in Hubertus de Salinis' Gloria »Jubilacio $\ll,{ }^{95}$ das - wie eingangs erwähnt - im unmittelbaren Kontext des Konstanzer Konzils anzusiedeln ist und dessen Tropus nun seinerseits in aller expliziten Eindeutigkeit das Ende des Schismas thematisiert. Signifikanterweise liegt denn auch der einzige strukturelle Unterschied zum Gloria »Suscipe trinitas« darin, dass der Schlusschorus, der bei Ciconia noch in kunstvoller Polyphonie überhöht wird, von Hubertus in strikter, durch Pausen deutlich zäsurierter Homophonie gesetzt wird. So erhält die Thematik von Spaltung und Einheit in Verbindung mit symbolträchtiger Stimmenzahl und den Bezeichnungen »chorus « und »unus« durch Alternatim und satztechnische Varianz eine dezidiert klangräumliche Dimension, die sich nun in der Tat in einem Akt auditiver Präsenz unmittelbar in der musikalischen Performanz erschließt (so etwa auch in der chorischen Aufstellung der Sänger, man denke an die Bildfindung in der Richental-Chronik).

\section{Antikonziliarismus, Traditionsrückgriff und Überbietung}

Wie sich die hier kursorisch umrissene Vielfalt und Polyvalenz an Raumund Zeitdimensionen in papstbezogenen Kompositionen ins weitere 15. Jahrhundert hinein fortsetzt, mag zum Abschluss in einem knappen Ausblick auf die Musik im Umfeld von Martin V. sowie insbesondere mit dem

94 Anne Hallmark, »Some evidence for French influence in northern Italy, c. 1400«, in: Studies in the Performance of Late Medieval Music, hrsg. von Stanley Boorman, Cambridge 1983, S. 193225. Vgl. auch Bacco / Nádas, Verso uno stile internazionale< (wie Anm. 63).

95 Überliefert in: Bologna $Q$ 15, fol. $62^{\mathrm{v}}-64^{\mathrm{r}}$; Venedig 145, fol. $15^{\mathrm{v}}-19^{\mathrm{r}}$; Edition: CMM 11/VII, S. $34-40$. 
Fluchtpunkt auf Dufays Werke für Eugen IV. skizziert und perspektivisch zusammengefasst werden. So begegnet bei Martin V., der sich durch die im Dekret Frequens festgeschriebenen regelmäßigen Konzilien massiv des Privilegs der Überzeitlichkeit und `ewigen< Gültigkeit päpstlicher Beschlüsse beraubt sah, ${ }^{96}$ eine besonders intensive Reflexion von Zeitlichkeit in der Musik; und zwar nicht nur mit den schon zuvor erwähnten Rondeaux auf der Traditionslinie volkssprachlicher >formes fixes<, sondern - in einer Art Bündelungs-, Engführungs- und Überbietungsstrategie der Traditionen, die man im Sinne von Kontinuitätsstiftung als ein Grundprinzip kirchlicher Legitimationsbildung begreifen kann - auch wieder im musikalischen Modus hochkomplexer Motetten.

Neben Johannes Brassarts Te dignitas presularis ${ }^{97}$ und Magne deus potencie | Genus regale esperie (mit ausgiebigem kanonisch geführten Introitus, lateinischem Kanon und stenor ad longum $<$ ) ${ }^{98}$ in denen in der Tat viele der zuvor genannten Aspekte und Strategien zeitlichen und räumlichen Verweisens zusammengefasst scheinen, erweist sich der dezidierte Rekurs auf Momente der Temporalität und zeitlichen Komplexität dabei insbesondere in dem Antonio de Cividale zugeschriebenen Clarus ortu | Gloriosa mater ecclesia | Justus non conturbabitur ${ }^{99}$ als bemerkenswert. Denn dem Text, der - in Vereinigung geläufiger panegyrischer Motive - räumlich auf eine Rückeroberung Palestinas sowie auf das »felix Roma« als angestammtem Ort des Heiligen Stuhls deutet (Cantus I), den »orbis sacris« beschwört, mittels Moses, Noah, David und Jacob in die biblische Vorzeit verweist und Bezüge zur Sukzession des römischen Kaisertums herstellt, um mit dem Schlussvers »facit ut pateant celesti regna beatis s schließlich noch einmal nachdrücklich die Position des Papstes als >mediator Dei et hominum< zu unterstreichen, steht eine höchst delikate kompositorische Anlage gegenüber, in der das in zwei Teilen insgesamt $3+6=9$ Taleae umfassende Stück durch vielfache Moduswechsel geprägt ist. Und genau diese, nicht zuletzt die Ausführenden extrem herausfordernde musikalische Komplexität scheint in dem (aus einem

96 Vgl. Birgit Studt, Papst Martin V. (1417-1431) und die Kirchenreform in Deutschland, Köln u.a. 2004 (Forschungen zur Kaiser- und Papstgeschichte des Mittelalters, 23).

97 Überliefert in: Bologna Q 15, fol. $266^{\mathrm{v}}-267^{\mathrm{r}}$; Trient 87, fol. $77^{\mathrm{v}}-78^{\mathrm{v}}$; Edition: CMM 352, S. 8 10.

98 Überliefert in: Bologna Q 15, fol. 253 $-254^{\mathrm{r}}$; Edition: CMM 352, S. 24-26. Der Kanon lautet: $»$ Iste dicitur bis primo de modo et tempore perfectis secundo per tercium sed prime pause non dicuntur«.

99 Überliefert in: Oxford 213, fol. $117^{\mathrm{v}}-118^{\mathrm{r}}$; Edition: Charles van den Borren, Polyphonia sacra, Burnham 1928, ${ }^{2} 1963$, Nr. 23 (S. 150-158). 
seinerzeit schon obsolet gewordenen, jedenfalls nicht eigentlich mehr aktuellen Graduale für das Proprium der alten Stephansliturgie entnommenen) Tenor zugleich ironisch bzw. espritvoll-vielsinnig kommentiert: »Justus non conturbabitur quia Dominus firmat manum «. ${ }^{100}$ - Angesichts der im Dekret Frequens manifest gewordenen Zweifel gegenüber einer überzeitlichen Unfehlbarkeit päpstlicher Erlasse ist dies eine nicht wenig brisante Aussage, die die reale Machteinbuße des Pontifex in Musik gleichsam kompensatorisch auffängt und dem Heiligen Vater zumindest im musikalischen Kontext göttliche Legitimation und Souveränität zuspricht.

\section{Papalismus, Reformfragen, Kulmination und Wandel}

Eine neue Qualität erhalten papstbezogene Zeit- und Raumaspekte freilich bei Guillaume Dufay unter Eugen IV., ${ }^{101}$ der die päpstliche Suprematie streitbar gegen das Konstanzer Dekret Haec sancta, das die Vorrangstellung des Konzils gegenüber dem Papst definiert hatte, verteidigte ${ }^{102}$ und zugleich ab 1433 in intensive Verhandlungen um eine Union mit der Ostkirche trat, ehe er dieses Ziel 1439 erreichte, zugleich freilich durch den schismagleichen Konflikt zwischen den Reformkonzilien in Basel / Lausanne und Ferrara / Florenz sowie mit dem Gegenpapst Felix V. erneut harsche Widerstände erfuhr. Dass Eugens Autorität besonders eindringlicher Betonung bedurfte und sich in diesem Sinne auch in Dufays Papstkompositionen vor allem Raum- und Zeitaspekte eingeschrieben finden - und zwar gewissermaßen als Summa bzw. Fluchtpunkt aller bisherigen Techniken -, erscheint also durchaus folgerichtig.

In der Tat wäre den entsprechenden, insgesamt überaus gut erforschten ${ }^{103}$ Stücken denn auch eine eigene Studie zu widmen, in der es herauszu-

$100 »$ Der Gerechte wird nicht verwirrt, da er durch des Herren Hand gefestigt wird«. Vgl. insgesamt zu diesem Stück auch Robert Michael Nosow, The Florid and Equal-Discantus Motet Styles of Fifteenth-Century Italy, PhD Diss. Univ. of North Carolina, Chapel Hill 1992, S. 73-76.

$101 \mathrm{Zu}$ Eugens Repertoire vgl. auch Michael Phelps, A Repertory in Exile: Pope Eugene IV and the MS Modena, Biblioteca Estense Universitaria, a. X.1.11., PhD Diss. New York Univ. 2008.

102 Vgl. zuletzt Michiel Decaluwé, A successful defeat. Eugene IV's Struggle with the Council of Basel for Ultimate Authority in the Church, 1431/1449, Turnhout 2010 (Bibliothèque de l'Institut historique belge de Rome, 59).

103 Stellvertretend für die Vielzahl an einschlägiger und für die hier dargelegte Problematik höchst instruktiver Literatur zu Dufay: Laurenz Lütteken, Guillaume Dufay und die isorhythmische Motette. Gattungstradition und Werkcharakter an der Schwelle zur Neuzeit, Hamburg 1993 (Schriften zur Musikwissenschaft aus Münster, 4); Julie E. Cumming, The Motet in the Age of Dufay, 
stellen gälte, wie der aus dem 14. und beginnenden 15. Jahrhundert stammende Fundus an kompositorischen Strategien des musikalischen Zeit- und Raumbezugs von Dufay ausgeschöpft und erweitert wird, welche neue Qualität diese Momente dabei erfahren und wie dies wiederum insgesamt in Hinblick auf das päpstliche Selbstverständnis und den Repräsentationsanspruch (bzw. -druck) Eugens zu deuten wäre. Nicht zuletzt entscheidend scheint dabei die Beobachtung, dass die überkommenen Mechanismen und Phänomene hier nicht nur gleichsam gebündelt und forciert erscheinen, sondern erstmals nachweislich aus dem Bereich der >musica reservata< in einen dezidiert liturgisch-zeremoniellen Rahmen transferiert sind -- ein bemerkenswertes und eingedenk aller Überlieferungsproblematik wohl auch weitgehend singuläres Phänomen, das im weiteren Verlauf des 15. Jahrhunderts allenfalls noch einmal punktuell etwa bei Johannes Pullois ${ }^{104}$ greifbar wird, ansonsten indes hinter Entwicklungen zurückzutreten scheint, die die >maiestas papalis< in anderen Kontexten und Konfigurationen repräsentierten.

In auffälliger zeitlicher Parallele zum Ende der »Zeit der Zerreißproben $\aleph^{105}$ und einer nach den Reformkonzilien wieder weitgehend konsolidierten Position von Pontifex und römischer Kurie jedenfalls scheinen sich die spätmittelalterlichen Verfahren vielschichtig-komplexer, auf den Spezifika des Mediums Musik gründender Raum- und Zeitbezüge in explizit papstbezogenen Kompositionen ab der Mitte des 15. Jahrhunderts zusehends überholt zu haben. Im Spannungsfeld zwischen Hermeneutik und Präsenz weichen sie offenbar neueren Strategien und Zielsetzungen, bei denen das Repräsentations- und Inszenierungsbedürfnis der Päpste im Zeichen der innerkirchlichen Reformen und ekklesiologischen Umbrüche offenbar trotz deutlich papalistischer Tendenzen (und eingedenk aller weiterhin höchst virulenten machtraumpolitischen Fragen ${ }^{106}$ ) weniger auf ostentative >maiestas<,

Cambridge 1999; sowie Peter Gülke, Guillaume Du Fay. Musik des 15. Jabrhunderts, Stuttgart 2003.

104 Vgl. etwa Gerald Montagna, »Johannes Pullois in context of his era «, in: Revue belge de musicologie 42 (1988), S. 83-117.

105 Vgl. oben, wie Anm. 20.

106 Vgl. etwa Erich Meuthen, »Reiche, Kirchen und Kurie im späteren Mittelalter«, in: Historische Zeitschrift 265 (1997), S. 597-637; sowie Götz Rüdiger Tewes, Die römische Kurie und die europäischen Länder am Vorabend der Reformation, Tübingen 2001 (Bibliothek des Deutschen Historischen Instituts in Rom, 95). Siehe insgesamt auch Heribert Smolinsky, »Papstgewalt ohne Grenzen? Papalistische Theorie im Zeitalter der Renaissancepäpste und des römischitalienischen Humanismus«, in: Rottenburger Jahrbuch fïr Kirchengeschichte 11 (1992), S. 7183. 
Distinktion und Exklusivität denn auf Gemeinschaftsstiftung und den Gedanken von >modestia< und >umilità gerichtet ist. ${ }^{107}$

Im Sinne einer letzten Kulmination und Summa der für die Dekaden um 1400 diagnostizierten Wirkungs- und Funktionsmechanismen sowie ihres Transfers in einen deutlicher präsentisch-ereignisbezogenen liturgischen Kontext jedenfalls markieren die Papstkompositionen bei Guillaume Dufay auf ebenso paradigmatische wie exzeptionelle Weise eine letzte Blüte. Hier nurmehr stichwortartig erinnert sei etwa an folgende Phänomene:

- an die an Ciconia und Salinis gemahnende gegenchörig-antiphonische Anlage des Sanctus papale mit seiner systematischen Weitung von der Einstimmigkeit über die Zwei- und Dreistimmigkeit hin zur Vierstimmigkeit mit weiterer Auslotung des Klangraums bis zur zeitweisen Sechsstimmigkeit; ${ }^{108}$

- an das räumliche Übereinander zweier isorhythmischer Grundgerüste sowie die daraus resultierende, höchstkomplex geschichtete Zeitstruktur in Ecclesia militantis, wo sich die Dreigliedrigkeit des zeitlichen Verlaufs gewissermaßen in der dreischichtigen vertikalen Klangraumstruktur durch die unterschiedlichen Stimmfakturen spiegelt (lapidar-prägnante Tenores vs. liedhafter Contratenor vs. lebhaft figurierende Tripla);

- an die bei aller präsentischen Unmittelbarkeit und melodischen Kraft hochkomplexe pan-isorhythmische Struktur mit gleich in doppelter Weise rückläufig bzw. krebsgängig organisiertem Tenor in dem durch das >Agnus Dei<-Ritual auch symbolisch-politisch (mit Blick auf Konstantinopel) aufgeladene Balsamus et munda cera, ${ }^{109}$ das durch seine zeremonielle Einbindung

107 Im Zuge einer wachsenden Brisanz der Reformfrage ändern sich bekanntlich die Repräsentationsstrategien vieler Päpste zugunsten einer schärferen Trennung zwischen Amt und Person, wobei gerade die Zurschaustellung von smaiestas kontrovers diskutiert wird - darunter insbesondere eben auch die Rolle zeremonieller Mehrstimmigkeit, wie sie sich gleichzeitig immer lauter werdender Kritik gegenüber sieht. Nicht zuletzt mag in dem vielschichtig-komplexen Gefüge der Umbruchszeit der generelle musikalische Stil- und Geschmackswandel ( Contenance angloise <etc.) wichtige Impulse gesetzt haben.

108 Dem (klang-)räumlichen Konzept des Sanctus steht in dem möglicherweise auch von Dufay stammenden Agnus »Custos et pastor ovium« die forcierte Auslotung der Zeitlichkeit gegenüber: Im Rahmen der für einen Messsatz per se ungewöhnlichen Isorhythmie wird der Cantus in einem ersten Abschnitt (Agnus Dei) einmal durchlaufen und dann krebsgängig zurückverfolgt, in einem zweiten Abschnitt (qui tollis pecata mundi) zweimal im Verhältnis 2:1 präsentiert und im dritten Abschnitt (miserere nobis) dann dreimal in Proportion formuliert. Zudem kann man das Stück mit Gülke, Guillaume Du Fay (wie Anm. 103), S. 92, plausibel und für die hier verfolgte Fragestellung aufschlussreich als »Etüden im Nicht-enden-Wollen« interpretieren.

109 Neben der genannten Literatur vgl. zudem: Craig Wright, »Dufay's motet Balsamus et munda cera and the papal ceremony of the Agnus Dei«, in: Music and medieval manuscripts. 
zudem ganz deutlich einen heilsmächtigen Charakter entfaltet und daher mit Peter Gülke fraglos »als perpetuiertes Jetzt, als reversible Zeitlichkeit «, als »zeitaufhebende >Augenblicklichkeit $<$ der Musik « gedeutet werden kann; ${ }^{110}$

- sowie an die transparente, rezeptionsorientiert plastische, nichtsdestoweniger hintergründig vermittelte Gestalt in Supremum est mortalibus mit seinen betont markanten Abschnittsbildungen.

Nicht zuletzt besonders hervorzuheben sind schließlich die vielbeschriebenen Architektur-Analogien und Proportionen, die symbolträchtige snumerositas $<$, die Spiegelungsmechanismen und klanglichen Steigerungsmomente bei Nuper rosarum flores, ${ }^{111}$ in Bezug auf das Giannozzo Manetti in seinem berühmten Bericht zur Florentiner Domweihe abschließend - und gerade in all seiner formelhaften Rhetorik und toposbeladenen Stilisierung, die die weite Verbreitung und >longue durée< dieser Wahrnehmungsperspektive belegen mag - noch einmal nachdrücklich die aller Hermeneutik und rationalen Deutungsarbeit stets zur Seite stehende Präsenz und performative Ereignishaftigkeit von Musik als mystische Jenseitsschau und anrührende ssancta imaginatio< vor Augen halten mag. ${ }^{112}$

Paleography and performance, hrsg. von John Haines und Randall Rosenfeld, Aldershot 2004, S. 325-348.

110 Gülke, Guillaume Du Fay (wie Anm. 103), S. 16lf.

111 Neben der genannten Literatur vgl. zudem: Hans Ryschawy und Rolf W. Stoll, »Die Bedeutung der Zahl in Dufays Kompositionsart: Nuper rosarum flores«, in: Guillaume Dufay, hrsg. von Heinz-Klaus Metzger und Rainer Riehn, München 1988 (Musik-Konzepte, 60), S. 3-73; Anne-Marie Mathy, »La consécration de la cathédrale de Florence par le pape Eugène IV. Musique, poésie, architecture«, in: Musica e immagine (wie Anm. 8), S. 87-108; sowie Michał Zieliński, »Symbolism of numbers and its importance in aural perception (Illustrated by the motet Nuper rosarum flores by Guillaume Dufay) «, in: Dzieto muzyczne jako fenomen dźwiękowy | The musical work as a sound phenomenon, hrsg. von Anna Nowak, Bydgoszcz 2007, S. 83-93.

$112 »$ Dabei gab es überall ein Singen mit so vielen und verschiedenen Stimmen, und soviel Wohlklang stieg zum Himmel, daß es dem Hörer wahrhaftig wie ein Konzert göttlicher und von Engeln gesungener Melodien erschien. Die Stimmen erfüllten die Ohren der Zuhörer mit so wunderbarer Süße, daß sie betäubt zu werden schienen fast wie Menschen, die ihrer nicht mehr mächtig sind, weil sie Sirenen singen hören. ... die Musik der Engel und des himmlischen Paradieses [schien] vom Himmel herabgesandt, um unseren Ohren eine unfaßliche Süße zuzuflüstern. Weshalb ich in diesem Augenblick so sehr von Ekstase überkommen war, daß es mir schien, als genöße ich das Leben der Himmlischen schon auf der Erde. Ob es anderen Anwesenden ebenso erging, weiß ich nicht, aber was mich selbst betrifft, kann ich es bezeugen.« Zitiert nach: Sabine Zak, »Der Quellenwert von Giannozzo Manettis Oratio über die Domweihe von Florenz 1436 für die Musikgeschichte«, in: Die Musikforschung 40 (1987), S. 2-32, hier: S. 14f. Zur zentralen Kategorie der suavitas« vgl. jüngst Gregor Herzfeld, »Süße: Eine Metapher der mittelalterlichen Musiktheorie«, in: Archiv für Musikwissenschaft 69 (2012), S. 1-12. 